Contract No. W-7405-eng-92

\title{
EFFECTS OF TERNARY ADDITIONS ON ALUMINUM-35 w/O URANIUM ALLOYS
}

\section{by}

Norman E。 Daniel

Ellis I. Foster

Ronald F. Dickerson

\section{UNGLASSTFLD}

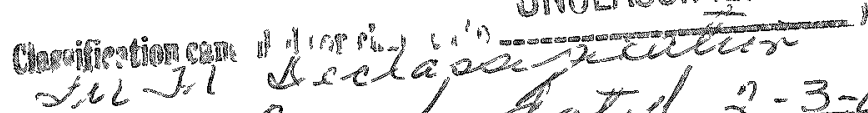

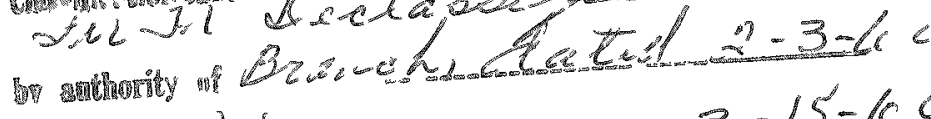

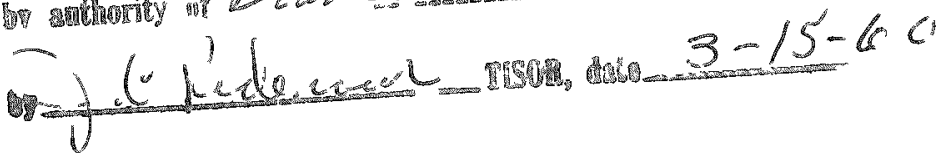

October 27,1959

\section{RESTRICTED DATA}

This document contains restricted data as defined in the Atomic Energy Ach of 1954. Its transmittal or disclosure of its contents in any manner to an unauthorized person is prohbited.

BATTELLE MEMORIAL INSTITUTE $505 \mathrm{King}$ Avenue

Columbus 1, Ohia

CONFIDENTIAL 


\section{DISCLAIMER}

This report was prepared as an account of work sponsored by an agency of the United States Government. Neither the United States Government nor any agency Thereof, nor any of their employees, makes any warranty, express or implied, or assumes any legal liability or responsibility for the accuracy, completeness, or usefulness of any information, apparatus, product, or process disclosed, or represents that its use would not infringe privately owned rights. Reference herein to any specific commercial product, process, or service by trade name, trademark, manufacturer, or otherwise does not necessarily constitute or imply its endorsement, recommendation, or favoring by the United States Government or any agency thereof. The views and opinions of authors expressed herein do not necessarily state or reflect those of the United States Government or any agency thereof. 


\section{DISCLAIMER}

Portions of this document may be illegible in electronic image products. Images are produced from the best available original document. 


\section{ABSTRACT \\ INTRODUCTION \\ EXPERIMENTAL PROCEDURES \\ Investigation of the Effects of 3 a/o Alloy Additions on the Structure and}

Page

Properties of the Aluminum-35 w/o Uranium Alloy . . . . . . . . 6

Evaluation.

Investigation of the Effects of Additions of Less Than 3 a/o on the

Structure and Properties of the Aluminum-35 w/o Uranium Alloy . . . 13

Evaluation . . . . . . . . . . . . . . . . 13

Preparation and Evaluation of 3-In.-Diameter Ingots Containing

$3 \mathrm{w} / 0$ Ternary Additions . . . . . . . . . . . . . . . . 23

Extrusion Studies . . . . . . . . . . . . . . 29

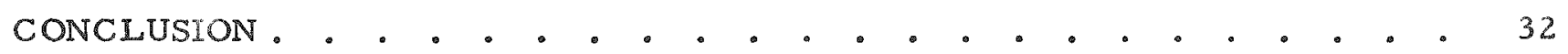

REFERENCES • • . . . . . . . . . . . . . . . . 33 


\title{
EFFECTS OF TERNARY ADDITIONS ON ALUMINUM- $35 \mathrm{w} / 0$ URANIUM ALIOYS
}

\begin{abstract}
Noman E. Daniel, Ellis L. Foster, and Ronald F. Dickerson
The effects of a number of ternary additions on the constitution, casting, and fabricating characteristics and the physical properties of aluminum-35 w/o uranium were investigated. Initial investigations were concerned with the effects of 3 a/o ternary additions on the microstructure and press-forging characteristics of the alloy. It was found that additions of this magnitude often introduced extrinsice phases in the alloy. At the 3 wo level, additions of germanium, silicon, tin, or zirconium inhibited the formation of VAl 4 and thereby increased the extent of the aluminum matrix in the alloy. It was also noted that these additions decreased the pressures required for extruding, and the tin addition also improved the homogeneity of cast shapes. Lead and palladium also improved the homogeneity of the cast material; however, neither of these us an effective inhibitor of UAl 4 and free lead was detected in the alloy to which lead had been added as the ternary.
\end{abstract}

From these studies it appears that tin and zirconium are as effective as silicon in enhancing the fabricating characteristics of aluminum-35 w/o uranium alloys, and may prove superior when evaluated on the bases of casting qualities and recycling characteristics.

\section{INTRODUCTION}

Aluminum-uranium alloys have been found to be satisfactory fuels for lowtemperature water-cooled water-moderated reactors. The bulk of the aluminumuranium alloys now being used as reactor fuels contain uranium concentrations of $20 \mathrm{w} / 0$ or less. Experience with the alloys in this system containing more than $20 \mathrm{w} / 0$ uranium has shown that these alloys exhibit relatively poor casting and fabricating characteristics. In order to use these higher uranium alloys, this condition must be circumvented either by some special casting and fabricating technique or by some modification of the alloys to improve these characteristics and thereby make them more amenable to fuel-element production.

The $m$ jor problems encountered in casting alloys containing more than $20 \mathrm{w} / 0$ uranium are inhomogeneity and lack of soundness in the ingots. The inhomogeneous condition produced by casting is attributed to the differences in densities of the phases present, and is aggravated by the wide freezing ranges of the alloys. The large compound particles which are formed during solidification give rise to a high settling $r$ ate; and the wide freezing range provides ample time during solidification for setting to take place.

The problems encountered in fabrication are the result of the large volume and the large particle size of the compounds in these alloys. During investigations at ORNL(1) it was found that certain elements when added in relatively small quantities would improve the fabricability of aluminum-uranium alloys containing up to $48 \mathrm{w} / \mathrm{O}$ uranium. The improvement obtained was attributed to the suppression of the peritectic reaction producing $\mathrm{UAl}_{4}$ at $740 \mathrm{C}$, thereby increasing the extent of the matrix and decreasing the amount of compound found in the cast material. One of the most effective additions investigated at ORNL was silicon, and the properties of aluminumuranium alloys containing this addition have been investigated in some detail. (2)

(1) References are at end of text.

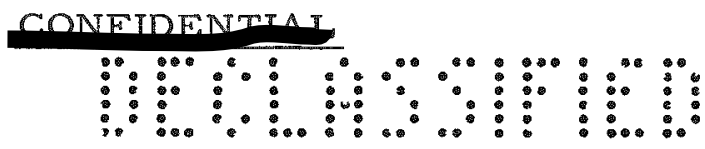


However, the presence of silicon in aluminum uranium fuel elements is objectionable since it causes a colloidal suspension to form when the spent fuel elements are recycled. This necessitates extensive changes in the reprocessing procedure.

Since the use of silicon in reactor fuels does introduce problems in recycling the spent fuel and since it was established that other elements could be used to inhibit the peritectic reaction, it was believed that improved alloys could be obtained by utilizing elements other than silicon for modifying the properties of these aluminum-uranium alloys. While decreasing the quantity of compound present by suppression of the peritectic reaction was the primary reason for modifying the alloys, it was thought that other changes in the alloys which would improve the casting quality as well as the fabricating characteristics might be realized through the proper selection of the addition. For this reason, a study concerned with the effects of ternary additions upon the aluminumm $35 \mathrm{w} / 0$ uranium alloy has been conducted.

\section{EXPERIMENTAL PROCEDURES}

Investigation of the Effects of 3 a/o Alloy Additions on the Structure and Properties of the Aluminum-35 w/o Uranium Alloy

Previous experience with the aluminum-35 w/o uranium alloys has indicated that they exhibit relatively poor fabrication characteristics. This is caused by the large volume of large UA1 4 particles present in the alloys. A logical approach to the improvement of the fabrication characteristics is through the suppression of $\mathrm{UAl}_{4}$ formation, thereby retaining $\mathrm{UAl}_{3}$ and increasing the amount of ductile aluminum matrix present in the alloys. If sufficient $\mathrm{UAl}_{3}$ cannot be retained, fabrication properties may be improved by the refinement of the $\mathrm{UAl}_{4}$ particle size or through strengthening of the matrix. It is possible that alloying additions may produce these changes and also improve the casting properties.

The choice of additions to be made to the alloys was governed to some extent by their compatibility with the chemical-reprocessing step, by their known effectiveness in retaining $\mathrm{UAI}_{3}$, and by their effect on other aluminum alloys. Copper, gadolinium, nickel, niobium, sodium, titanium, and zirconium were chosen for one or more of these reasons. Since silicon was known to suppress the UAl 3 -UAl4 reaction, it was postulated that this may have been due to the formation of USi3, and, therefore, other alloy additions were chosen on the basis of their similarity to silicon. Both USi 3 and $\mathrm{UAl}_{3}$ have the same crystal structure, and a difference in unit cell size of only 6 per cent suggests that the formation of a solid solution of UA13-USi3 is possible. Germanium, lead, palladium, platinum, and tin form compounds similar to USi3, and it was thought that the se might have the same effect upon the uranium-aluminum system as does silicon. It was recognized that some of these additions might not be suitable for use in fuel elements for reasons such as high cost or poor neutron economy. However, an evaluation of their effects upon the aluminum- 35 w/o uranium alloy was undertaken in the hope that the results would indicate the reasons for the increased fabricability exhibited by alloys containing silicon. It was also hoped that

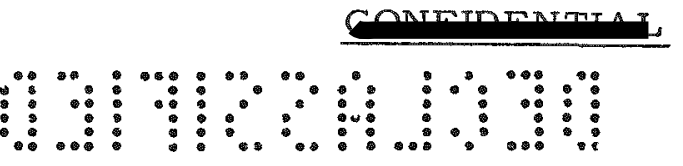


the results would indicate which alloy additions might be used to fulfill the requirements of increased fabricability and compatibility with the chemical-processing operations.

The initial melts in this series of alloys were made in the form of 1-in.-diameter by 8 -in. -long ingots cast in graphite molds. These melts were made from 99.99+ per cent pure aluminum and reactor-grade uranium. The aluminum was charged into a $\mathrm{ZrO}_{2}$ crucible and heated by induction to $930 \mathrm{C}$; the uranium was added and the melt temperature was increased to $1230 \mathrm{C}$; after holding 10 min the ternary addition was added to the melt. When it appeared that the addition was completely dissolved and the melt was homogeneous, the melt was lip poured into the graphite mold. Because of the small diameter of the induction coil and ceramic crucible, sufficient inductive stirring was obtained to eliminate the necessity for any manual stirring.

The as-cast ingots were radiographed and specimens were obtained for metallographic evaluation, room-temperature-hardness tests, and press-forging tests.

\section{Evaluation.}

The initial ingots containing 3 a/o ternary additions of the elements listed in Table 1 and ingots containing ternary additions of 1.68 a/o sodium, $10.40 \mathrm{a} / \mathrm{o}$ lithium, and 4.79 a/o magnesium were evaluated on the basis of soundness, microstructure, and press-forging characteristics. Prints of radiographs of these ingots are shown in Figures 1 and 2. It can be seen from these prints that the ingots containing gadolinium and lithium additions were extremely porous as was the initial ingot containing germanium. When each of the porous ingots was remelted an essentially sound ingot containing germanium was obtained. The ingots containing gadolinium and lithium remained porous. On the basis of the extreme porosity shown by these ingots, gadolinium and lithium were eliminated from further consideration at the time.

After radiographing, the ingots were sectioned and the asm cast structure of the alloys was examined by metallographic techniques. Figure 3 illustrates the microstructures resulting from the addition of the various elements listed in Table 1. An examination of these microstructures indicated that both germanium and tin were as effective as silicon in retaining $\mathrm{UA}_{3}$. The germanium addition resulted in an alloy containing a very clean matrix with little evidence of the eutectic. The palladium and tin alloys exhibited extremely fine microstructures. An examination of the microstructures of the alloy containing copper revealed the presence of three distinct phases. It was believed that an aluminum-copper phase was present in addition to an aluminum-uranium compound and aluminum. The alloys containing copper and niobium exhibited extremely coarse microstructures, and there was evidence of what was believed to be a niobium compound in the alloy. The examination of the alloy containing 3 a/o lead revealed the presence of what was interpreted to be free lead. The alloy containing zirconium exhibited a microstructure devoid of the angular compound particles found in the majority of the other alloys examined. The titanium alloy had considerable compound present which was somewhat oriented as evidenced from the stringers present in the microstructure. The only other microstructure suitable for comment is that exhibited by the alloy to which $1 \mathrm{w} / 0$ sodium was added. There was evidence of a peritectic reaction as shown by the reaction zones surrounding the primary compounds, and the particle sizes of the compounds themselves were small 


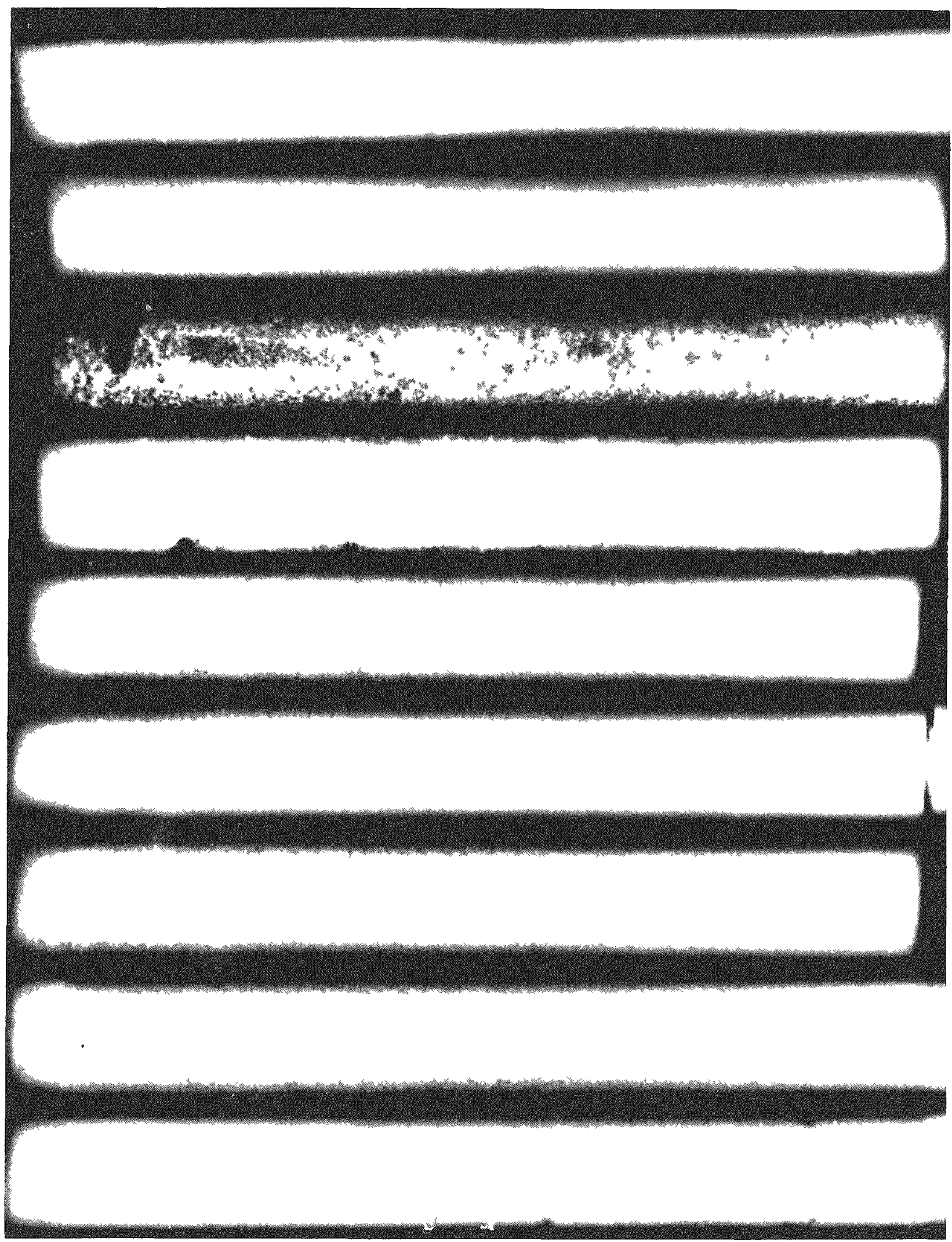

$1 \mathrm{X}$

TIGURE 1. RADIOGRAPHS OF AIR-CAST 1-IN.-DIAMETER ALUMINUM-35 W/O URANIUM INGOTS CONTAINING 3 a $/ 0$ ALLOY ADDITIONS

Note the extreme porosity in the ingot containing gadolinum.

\section{CONAIDENTTar}




\section{CONFIDENAL}

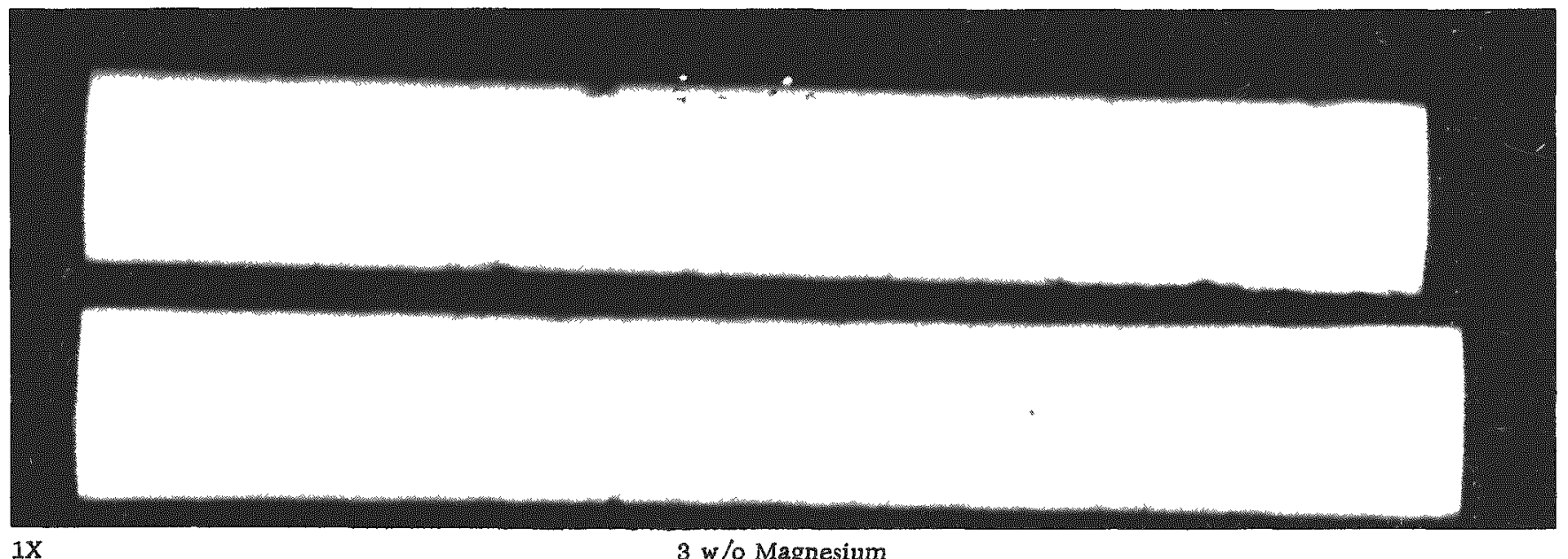

$1 X$

3 w/o Magnesium

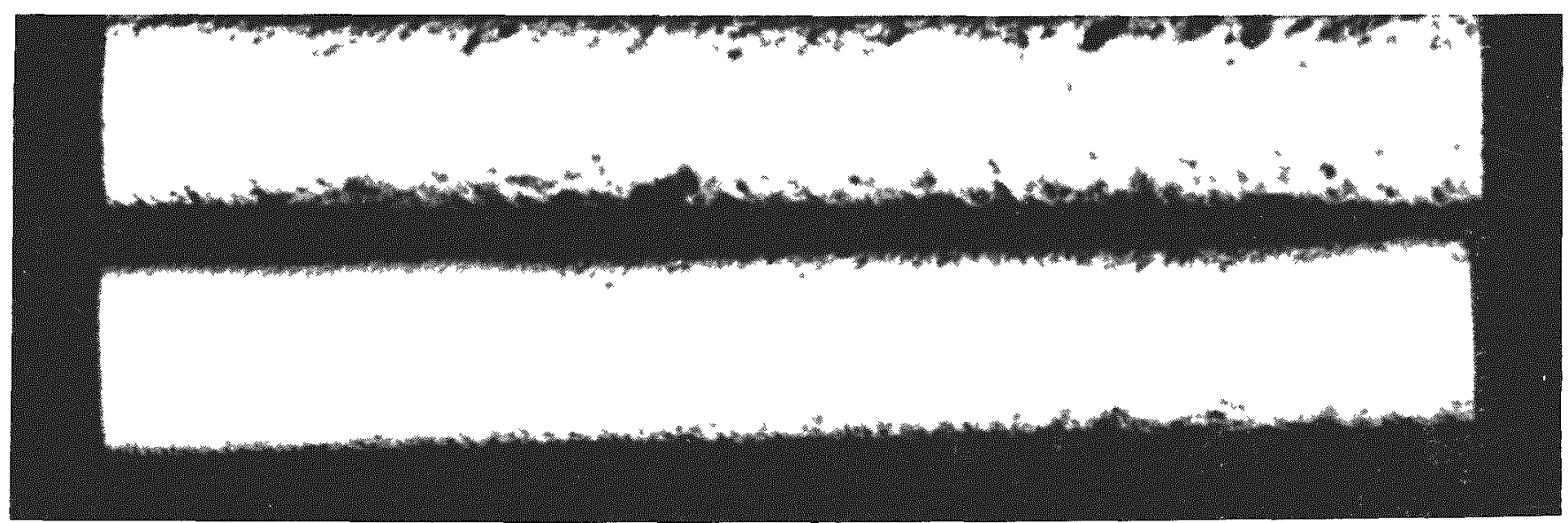

$2 \mathrm{w} / \mathrm{o}$ Lithium

FIGURE 2. RADIOGRAPHS OF AIR-CAST 1-IN.-DIAMETER ALUMINUM-35 w/o URANIUM INGOTS CONTAINING LITHIUM AND MAGNESIUM ADDITIONS

Lower ingot of each composition has been remelted once.

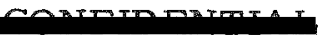

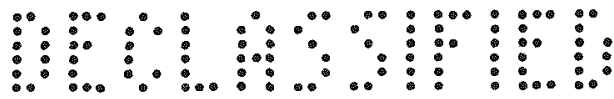




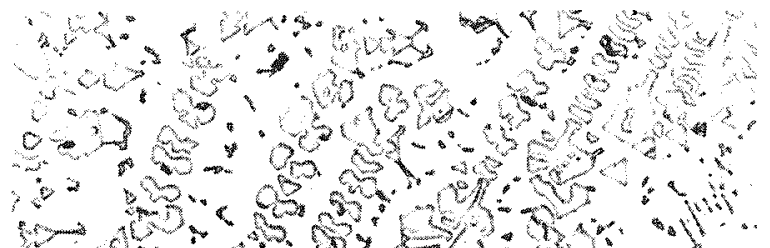

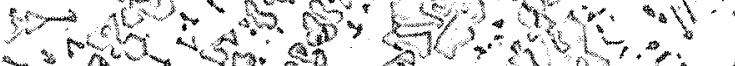

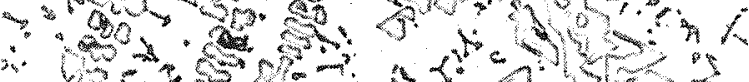

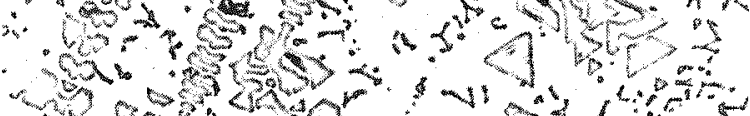

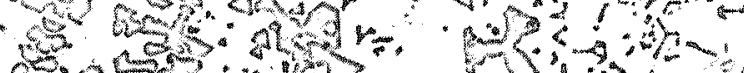

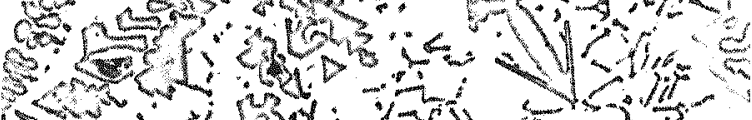

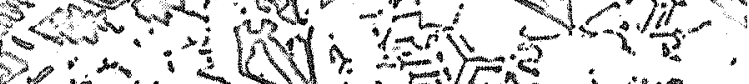

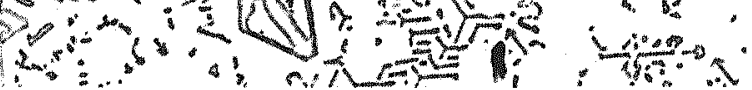
250X 3 a/o Germanium RM10734

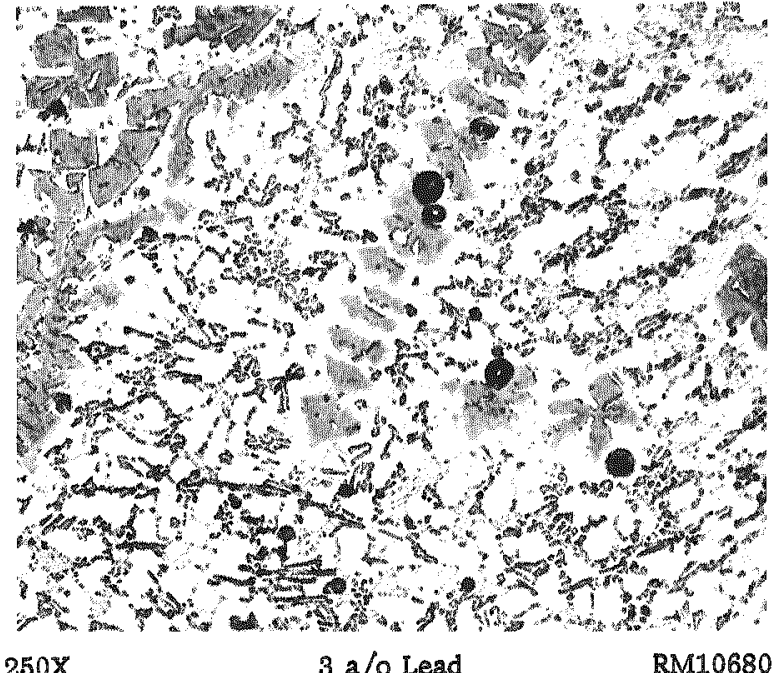

$250 \mathrm{X}$

3 a/0 Lead RM10680

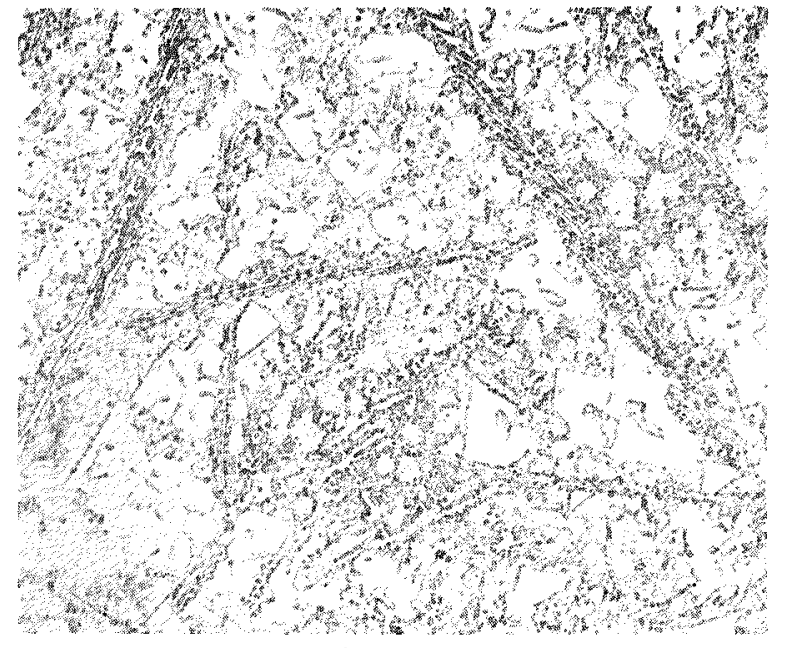

$250 \mathrm{x}$

RM10678
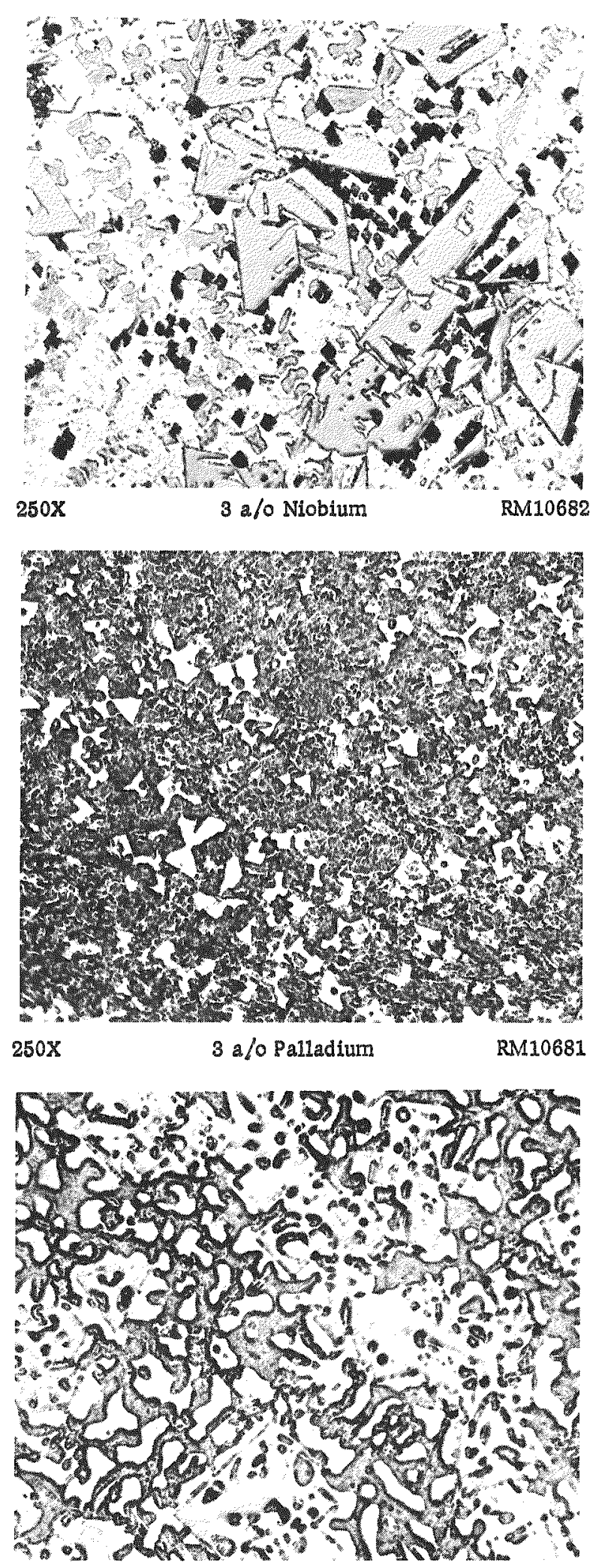

$250 \mathrm{X}$

3 a/o Copper

RM10683

FIGURE 3. MICROSTRUCTURES OF AS-CAST ALUMINUM-35 W/O URANIUM ALLOYS RESULTING FROM ADDITIONS OF VARIOUS ELEMENTS

Note the relatively clean continuous phase exhibited by the germanium alloy, the evidence of $\mathrm{NbAl}_{3}$ shown in the niobium alloy, and the fine microstructures of the palladium and tin alloys. Also of interest are stringerlike formations in the titanium alloy, the large quantity of compound in the copper alloy, and the absence of angular compound particles in the zirconium alloy. 


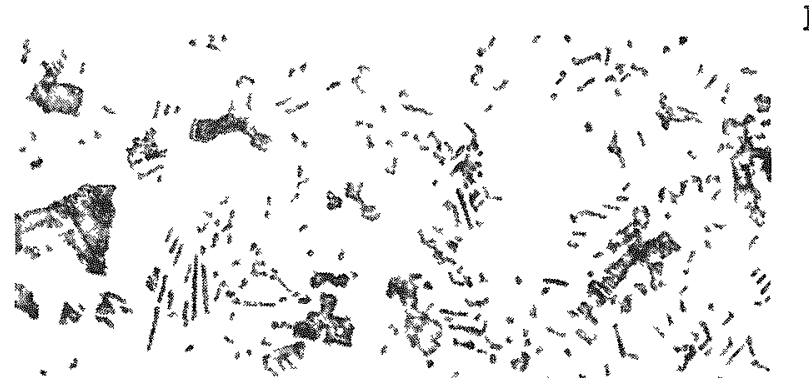

11
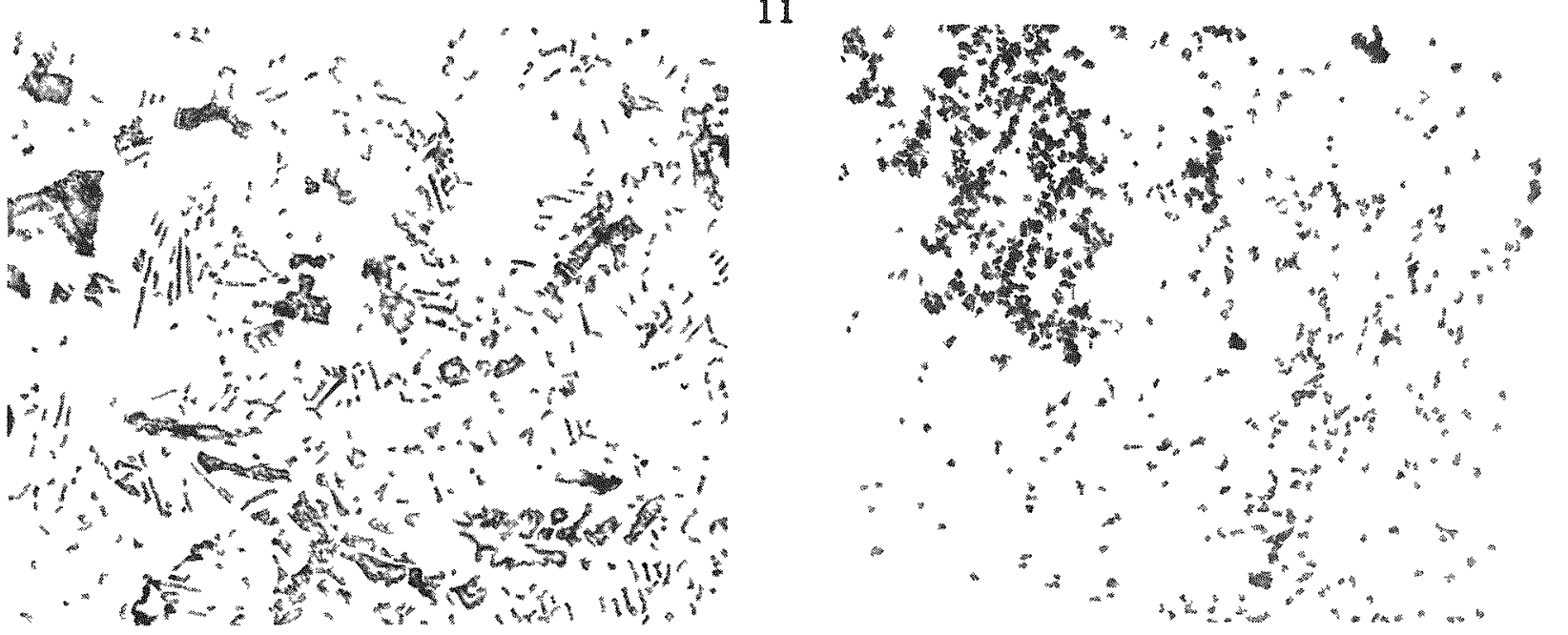

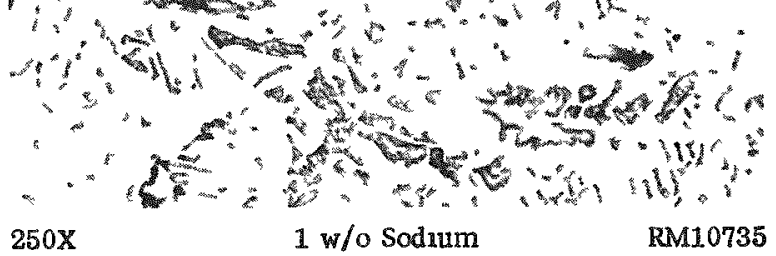

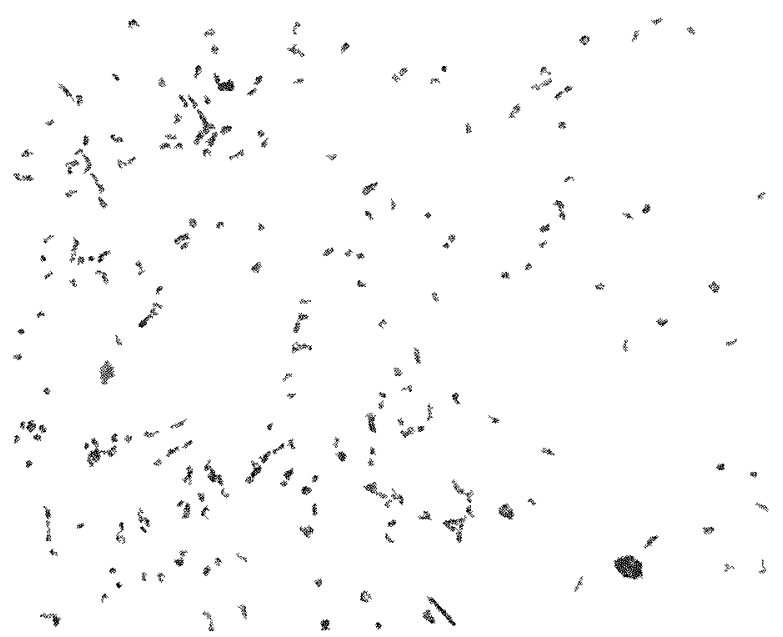

250X 3 a/o Sillcon RM10675

$250 \mathrm{X}$

3 a $/ 0$ Gadolunum

RM10679

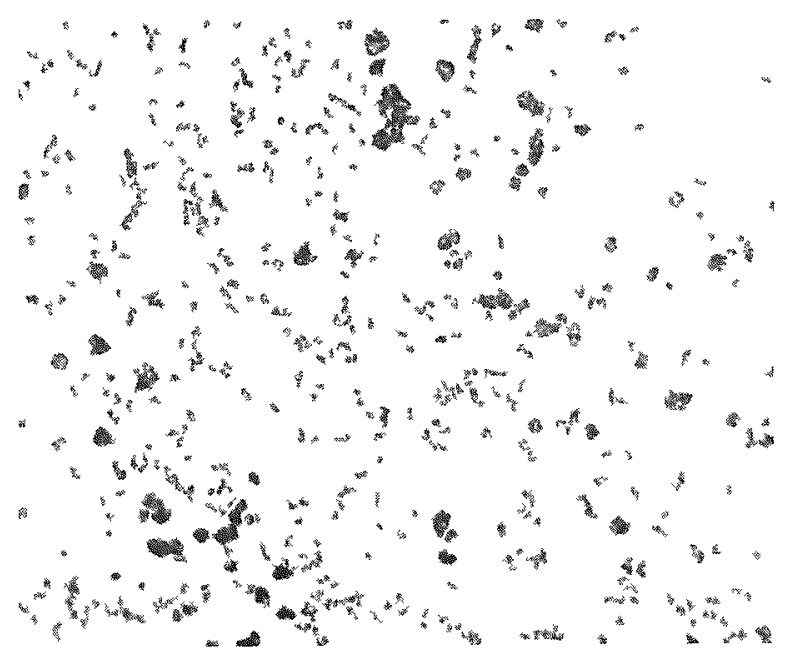

$250 \mathrm{X}$

$3 \mathrm{a} / \mathrm{o}$ Zrrconum

RM10677

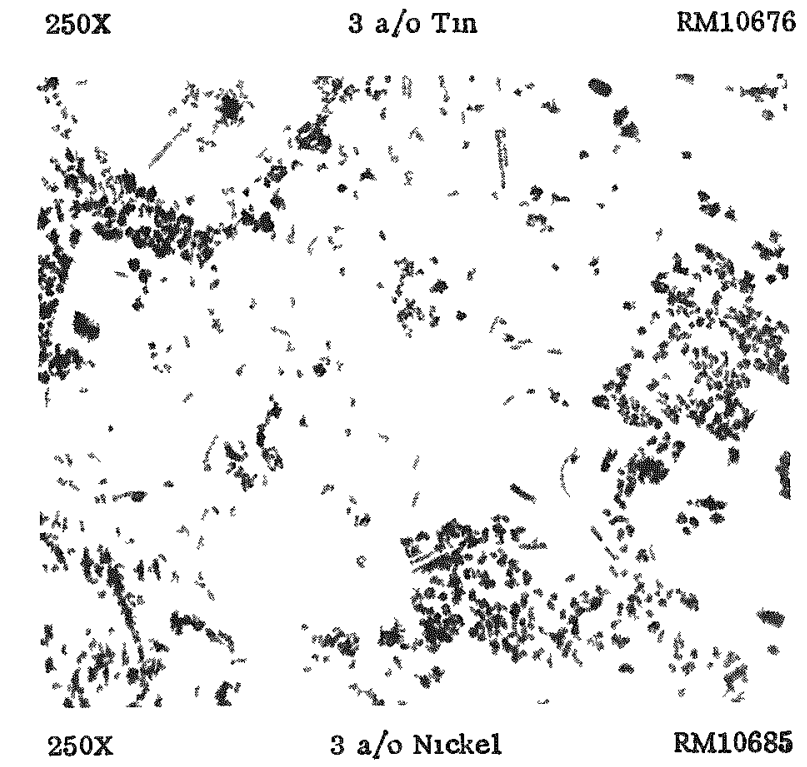

FIGURE 3. CONTINUED 
when compared with those in most of the other alloys. Attempts to reproduce this structure in two subsequent melts were unsuccessful; therefore, no sodium additions were evaluated in subsequent tests.

TABLE 1. EFFECT OF TERNARY ALLOY ADDITIONS ON ROOMTEMPERATURE HARDNESS OF ALUMINUM-URANIUM ALLOYS(a)

\begin{tabular}{llc}
\hline \multicolumn{1}{c}{ Alloy Addition } & \multicolumn{1}{c}{ w/o } & $\begin{array}{c}\text { Room- Temperature } \\
\text { Hardness, } \\
\text { DPH }\end{array}$ \\
\hline 3 silicon & 2.16 silicon & 65 \\
3 copper & 4.72 copper & 100 \\
3 niobium & 6.66 niobium & 98 \\
3 zirconium & 6.51 zirconium & 76 \\
3 tin & 8.25 tin & 52 \\
3 germanium & 5.28 germanium & 48 \\
3 palladium & 7.50 palladium & 97 \\
3 lead & 13.20 lead & 68 \\
3 nickel & 4.36 nickel & -- \\
3 titanium & 3.60 titanium & $-\infty$ \\
1.68 sodium & 1 sodium & -- \\
10.40 lithium & 2 lithium & - \\
4.79 magnesium & 3 magnesium & \\
\hline \hline
\end{tabular}

(a) Room-temperature hardness of aluminum-35 w/o uranium alloy was $65 \mathrm{DPH}$.

From the microstructures of the alloy it was apparent that copper formed an aluminum-copper phase by combination with the aluminum that would be found in the matrix of the binary aluminum-uranium alloy. Thus the effect of copper was to increase the amount of compound present in the alloy while reducing the amount of matrix present. However, it was thought that lesser quantities of the other elements tested might result in the elimination of the extrinsic phases detected in these alloys and effect an increase in the volume of the matrix of the alloys through retention of $\mathrm{UAl}_{3}$.

In addition to the metallographic examination, hardness determinations were made on a number of the alloys. It was found that the additions of copper, niobium, and palladium increased the DPH numbers of the alloys about 50 per cent. The hardness determinations are shown in Table 1. The only additions that decreased the hardness of the alloys were germanium and tin.

Other supplementary studies included thermal analysis and press forging. The thermal analyses were confined to the temperature range in which the peritectic $\mathrm{UAl}_{3}$ $\mathrm{UAl}_{4}$ reaction and the eutectic occur in the binary. Both heating and cooling curves were obtained. The results of the thermal analyses were inconclusive in that very

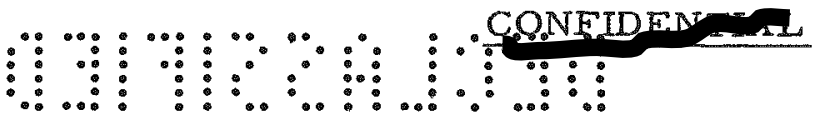


small or nonexistent thermal arrests were exhibited by all of the alloys in the region of the peritectic temperatures. All of the alloys with the exception of tin exhibited a pronounced thermal arrest at the eutectic temperature of the binary alloys. The thermal arrest was pronounced in the tin alloy but it occurred at approximately $600 \mathrm{C}$ rather than the $630 \mathrm{C}$ of the binary eutectic.

Specimens of the alloys were press forged at $540 \mathrm{C}$ to approximately 45 per cent reduction in length. The examination of these specimens revealed that only the palladium-containing alloy did not exhibit any evidence of microcracking.

From the metallographic examination and the press forging it was possible to conclude that additions on the order of 3 a/o were often excessive and gave rise to the formation of other compounds in the alloys which resulted in poorer fabricating characteristics. It was determined from the radiography that gadolinium and lithium resulted in increased porosity of sufficient magnitude to eliminate these additions from further consideration. Sodium as an addition was eliminated because it was difficult to reproduce its qualities. Therefore, it was decided that future tests would be confined to alloys containing additions of germanium, lead, nickel, niobium, magnesium, palladium, silicon, tin, and zirconium.

$\frac{\text { Investigation of the Effects of Additions of Less Than } 3 \text { a/o }}{\frac{\text { on the Structure and Properties of the Aluminum- } 35}{\mathrm{w} / 0 \text { Uranium Alloy }}}$

The investigations concerning the addition of 3 a/o ternary additions to binary aluminum-35 w/o uranium alloys showed rather conclusively that additions of this magnitude were not necessary for the retention of UA13. In fact, in many cases there was a sufficient excess of the additive to form another phase in the alloys. This spurious phase was formed at the expense of the matrix; thus the additions tended to decrease the $i$ nount of matrix present rather than increase it. Therefore, a series of alloys con aining lesser quantities of the ternary additions was prepared. On the basis of the effectiveness of the 3 a/o addition of silicon a series of alloys was made containing $3 \mathrm{w} / \mathrm{o}$ of the additions which appeared most promising from the initial studies. The method of preparing these alloys was identical to that used to prepare the previous alloys.

\section{Evaluation}

The evaluation of this series of 1 -in -diameter ingots containing 3 w/o ternary additions was more exacting than the evaluation of the previous melts. The techniques employed included radiographic examination of the as-cast ingots, extensive metallographic examinations of as-cast and fabricated material, and X-ray diffraction studies of the compounds in the alloys.

The radiographic examination revealed that the porosity in the ingots was comm parable to that found in the ingots shown in Figures 1 and 2. While the radiograph of the magnesium-containing ingot indicated no macroporosity, the metallographic examination of this material revealed that extensive microporosity was present.

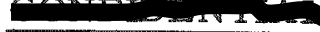


The metallographic examination of the asmcast material was performed on sections taken from the top and bottom of each ingot. Photomicrographs of specimens from each ingot are shown in Figure 4. A comparison of these photomicrographs with those shown in Figure 3 reveals that in a number of instances the extraneous phases noted in the alloys containing 3 a/o of ternary addition are diminished or completely eliminated in the alloys containing $3 \mathrm{w} / 0$ additions. In the germanium-containing alloys it will be noted that the alloy containing the smaller germanium addition exhibits the largest compound size. There is also a difference in the appearance of the continuous phase in the alloys. The matrix of the $3 \mathrm{w} / 0$ germanium alloy appears to contain more finely divided compound than does the alloy containing 3 a/o germanium.

In the case of the niobium-containing alloy the very dark phase which appears in the alloy containing $6.66 \mathrm{w} / \mathrm{o}(3 \mathrm{a} / \mathrm{o})$ niobium is almost nonexistent in the alloy containing $3 \mathrm{w} / 0$ niobium. It is believed that this phase is $\mathrm{NbAl}_{3}$. An examination of the alloy containing $3 \mathrm{w} / 0$ lead again reveals the presence of a phase believed to be free lead. This appears in the photomicrograph as an unetched area surrounded by a eutecticlike structure. In this photomicrograph and in the photomicrograph of the niobium-containing alloy there is evidence of a reaction zone around the primary compounds. X-ray diffraction studies substantiated the presence of both $\mathrm{UAl}_{3}$ and $\mathrm{UAl}_{4}$ in both of these alloys. The examination of the palladium-containing alloys revealed that the extermely fine particle size noted in the 3 a/o alloy $(7.50 \mathrm{w} / \mathrm{o})$ coarsened considerably when the alloying content was decreased. Further, the compounds formed an almost continuous phase in the casting, and there was evidence of the peritectic reaction as shown by the reaction zone around the larger compound particles. The alloy containing $3 \mathrm{w} / 0$ silicon appeared to be altered somewhat with the addition of the larger quantity of silicon. The microstructure of the alloy containing $3 \mathrm{a} / \mathrm{o}(2.16 \mathrm{w} / \mathrm{o})$ silicon exhibited an extensive eutectic phase, whereas the $3 \mathrm{w} / 0$ silicon alloy contained scattered areas of eutectic with the major portion of the compound existing in the massive state.

It was noted in the previous section that the addition of 3 a/o tin to the aluminum$35 \mathrm{w} / \mathrm{o}$ alloy resulted in an extremely fine microstructure. With the tin content decreased to $3 \mathrm{w} / 0$ the microstructure was coarsened; however, it was finer than that of the alloy containing silicon and exhibited none of the stringerlike compound formations that may be seen in the silicon alloy.

The microstructure of the alloy containing $3 \mathrm{w} / \mathrm{o}$ zirconium is also shown in Figure 4. This was very similar to that exhibited by the $3 \mathrm{w} / \mathrm{o}$ germanium alloy. There existed relatively large primary compound particles in a matrix containing scattered concentrations of the eutectic-type structure. It differed from the siliconcontaining alloy in that the compounds were more massive with less tendency to form stringerlike shapes. The alloys containing 3 w/o zirconium had a much cleaner matrix than did the alloy containing 3 a/o $(6.51 \mathrm{w} / \mathrm{o})$ zirconium. It is believed that the larger quantity of zirconium in the $3 \mathrm{a} / 0(6.51 \mathrm{w} / \mathrm{o})$ alloy formed the compound of $\mathrm{Al}_{3} \mathrm{Zr}$. To a very limited extent, the alloy containing the smaller additions of zirconium also contained this phase. When the alloy containing 3 a/o nickel was examined it was noted that an unidentified phase was present. At that time it was believed that a smaller quantity of nickel might reduce the quantity and extent of this phase. However, the metallographic examination of the $3 \mathrm{w} / \mathrm{o}$ nickel alloy revealed that a considerable quantity of this phase tentatively identified as $\mathrm{Al}_{3} \mathrm{Ni}$ was still 
present. The compound particles in the $3 \mathrm{w} / 0$ nickel alloy also exhibited reaction zones around their periphery which indicates that both $\mathrm{UAl}_{3}$ and $\mathrm{UAl}_{4}$ in addition to the $\mathrm{Al}_{3} \mathrm{Ni}$ and aluminum in the alloy existed in the alloy.

The observations made on the nickel alloy are applicable to the titanium-containing alloy. In the alloy containing 3 a/o titanium there existed what was thought to be an aluminum-titanium compound which occurred in the form of stringerlike particles. When the titanium addition was decreased these stringers disappeared; however, evidence of an aluminum-titanium compound remained. Furthermore, many of the compound particles exhibited reaction areas which suggests a peritectic reaction more sluggish than that of the $\mathrm{UAl}_{3}-\mathrm{UAI}_{4}$ reaction in the binary alloy.

The metallographic evaluation of these melts indicated that in a number of cases the $3 \mathrm{w} / 0$ addition was sufficient to retain the $\mathrm{UAl}_{3}$ without the formation of an extrinsic phase at the expense of the predominantly aluminum matrix. The melts containing $3 \mathrm{w} / 0$ nickel and titanium did not exhibit this behavior, and on this basis it was thought that the nickel and titanium additions offered little or no chance of improving either the fabrication or casting properties of the aluminum-uranium alloys. Therefore, the subsequent evaluations were made only on alloys containing germanium, lead, niobium, palladium, silicon, tin, and zirconium.

Press Forging. It was the purpose of the press-forging studies to gain an indication of the ability of the materials to be extruded. For these studies l-in. -1 long sections of each l-in,-diameter ingot were enclosed in a heavy-walled aluminum tube sealed with 1/2-in. - thick end caps. These specimens were then heated for $1 \mathrm{hr}$ in a furnace at $540 \mathrm{C}$ and press forged to a 50 per cent reduction in length. The specimens were then cut and transverse sections examined metallographically. Figures 5a, 5b, and $5 \mathrm{c}$ show photomacrographs of three of these specimens. The macroexamination. revealed numerous cracked areas in the specimens shown in Figures $5 \mathrm{a}$ and $5 \mathrm{~b}$. Metallographic examination of the specimens at magnifications of 250 and $500 \mathrm{X}$ revealed that in many cases what appeared as cracks on macroscopic examination were concentrations of compound particles which had been preferentially attacked by the etchant. The microstructures of the forged specimens are shown in Figure 6. An examination of these microstructures revealed that significant changes had taken place in the alloys containing germanium, lead, palladium, and silicon. In the germanium lead alloys the eutectic shown in the as-cast structure appeared to have spheroidized to a limited extent as a result of the fabrication. The compounds in the silicon alloy were cracked, and the palladium-containing alloy which formerly exhibited an almost continuous network of eutectic appeared to contain a modified eutectic dispersed throughout the material. The niobium-containing alloy shown at a magnification of $500 \mathrm{x}$ contained numerous cracks which upon inspection appeared to originate in the compound and followed paths of compound concentrations. The absence of a reaction zone surrounding compound particles in the lead and palladium alloys would indicate that the peritectic reaction has essentially gone to completion.

The photomicrograph of the tin alloy shown in Figure 6 was obtained from that area of the specimen which exhibited the largest compound-particle size. No changes attributable to fabrication of the alloy were detected in this specimen. The photomicrograph of the zirconium alloy represents an area of the specimen in which preferred orientation of the compounds was observed after fabrication. The compound

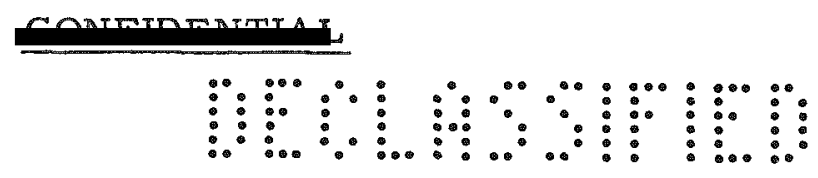


FIGURE 4. PHOTOMICROGRAPHS OF AS-CAST ALUMINUM-35 W/O URANIUM WITH 3 W/O ADDITIONS

Note the relatively clean contunuous phase exhubited by the germanum alloy, the evidence of $\mathrm{NbAl}_{3}$ in the mobuum alloy, and the evidence of free lead in the lead alloy. The sllicon, tin, and zirconium alloys all exhbit relatively clean matruxes. There is some rendency for the prumary compound to form dendriticetype structures in the silicon alloy. The titanum and tun microstructures show primary $\mathrm{UAl}_{3}$ particles which have reacted pertitectically to form $\mathrm{UAl}_{4}$.
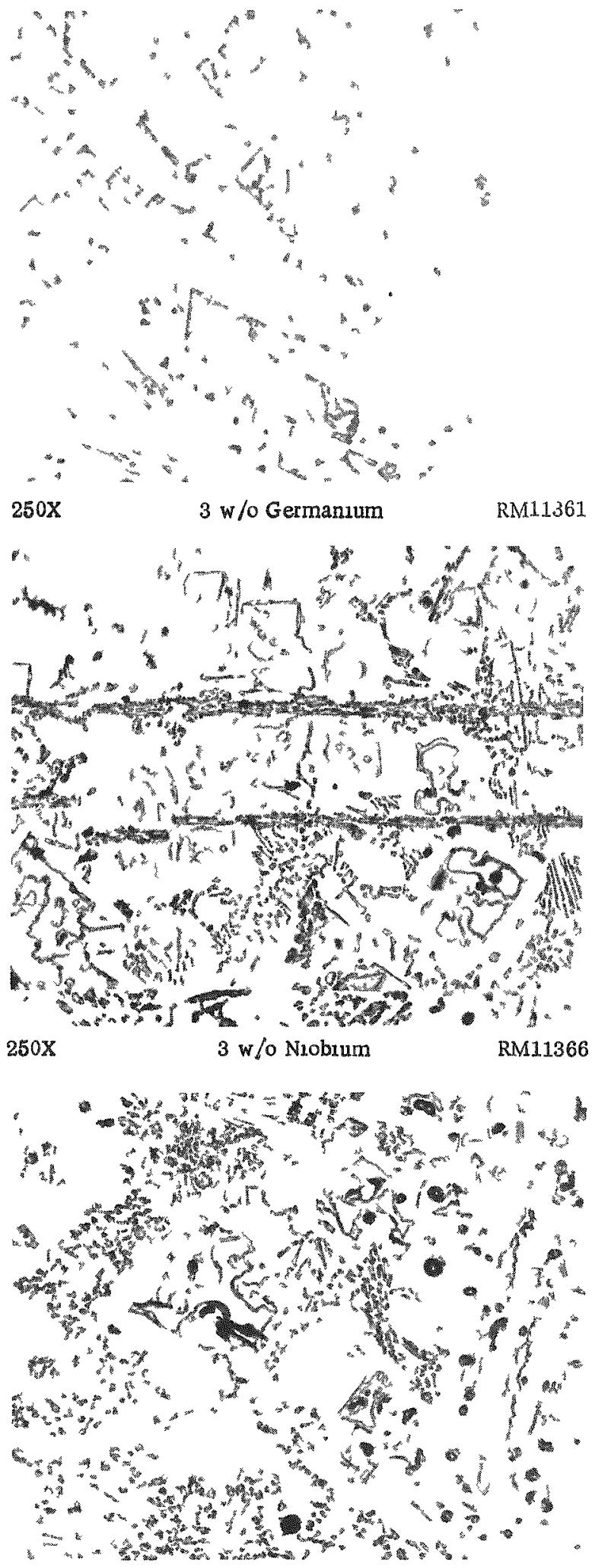

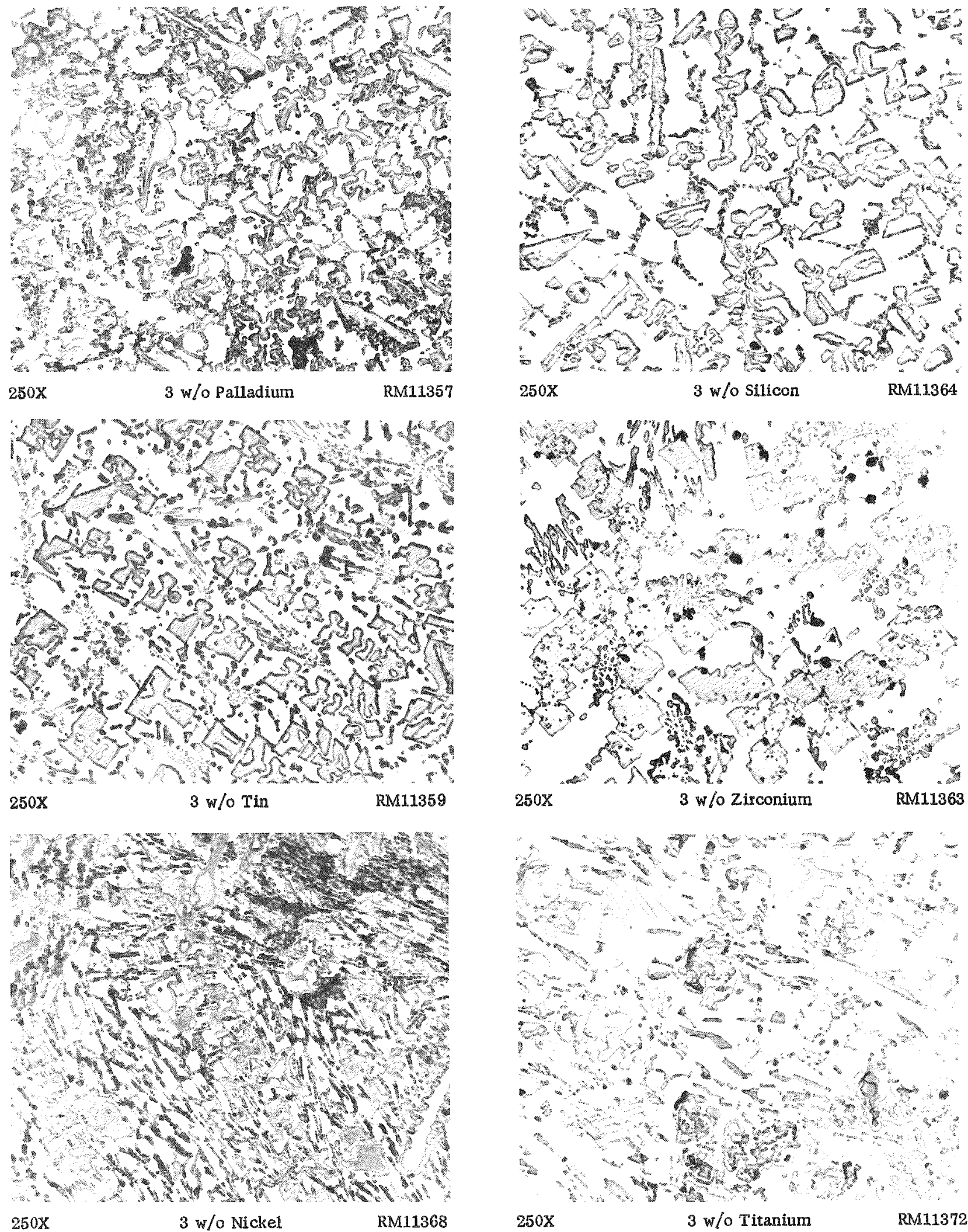

FIGURE 4. CONTINUED 


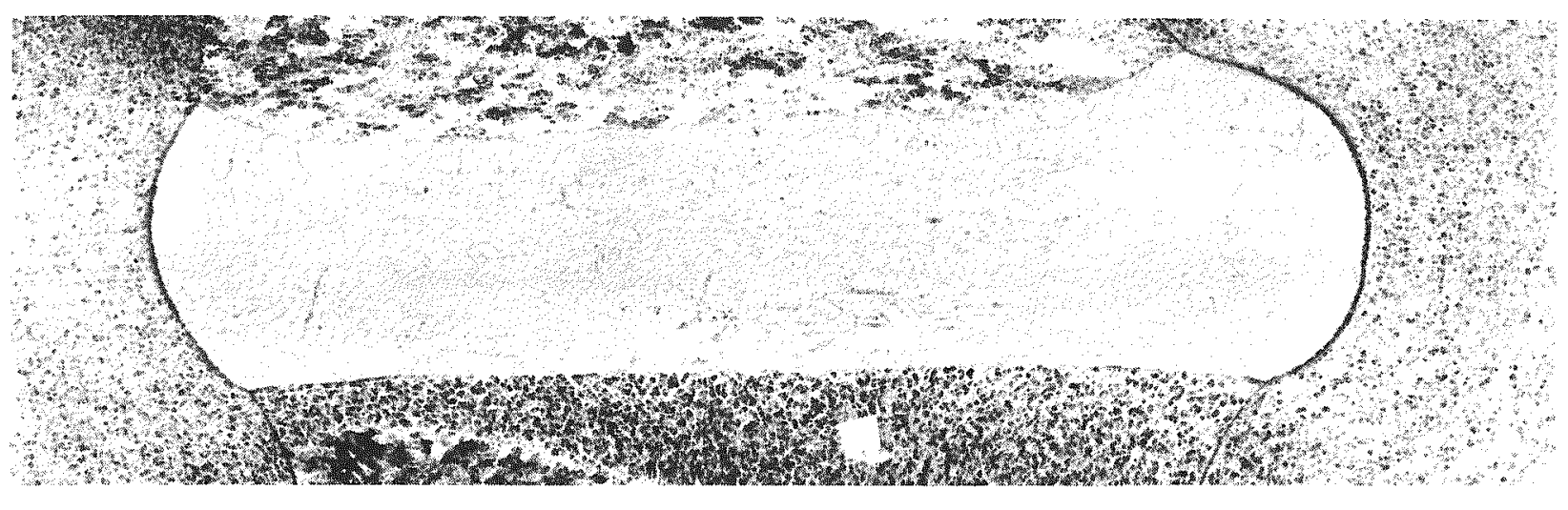

$7 \mathrm{X}$

a. Aluminum-35 w/o Uraniurn-3 w/o Lead

RM11475

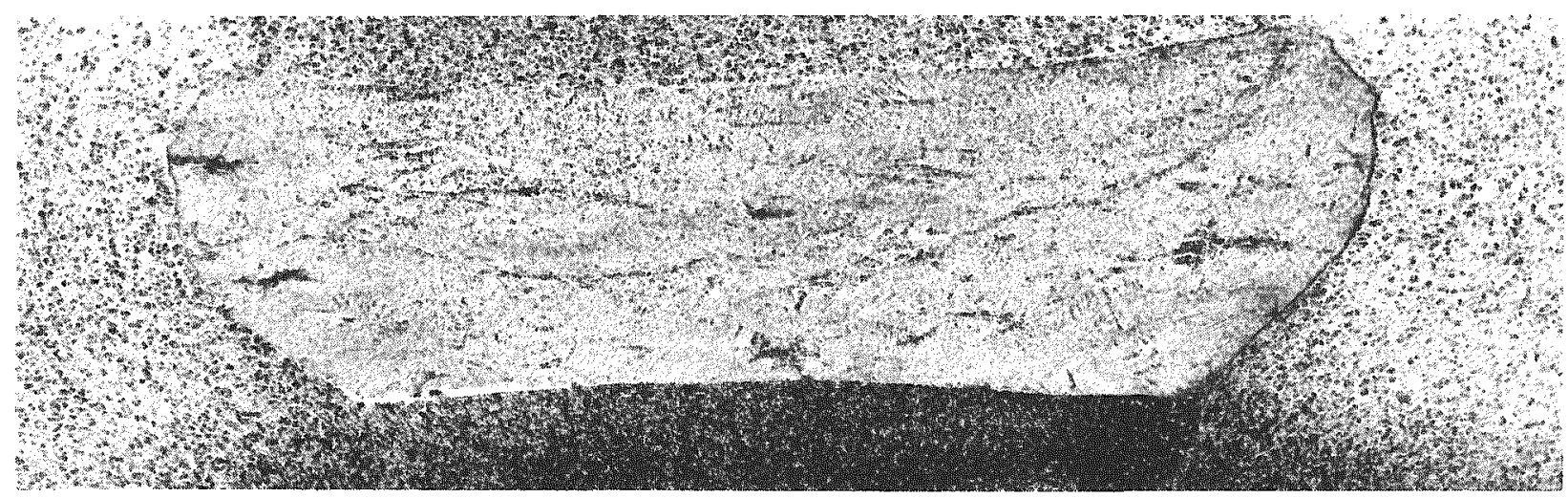

$7 X$

b. Aluminum-35 w/o Uranium-3 w/o Zirconium

RM11473

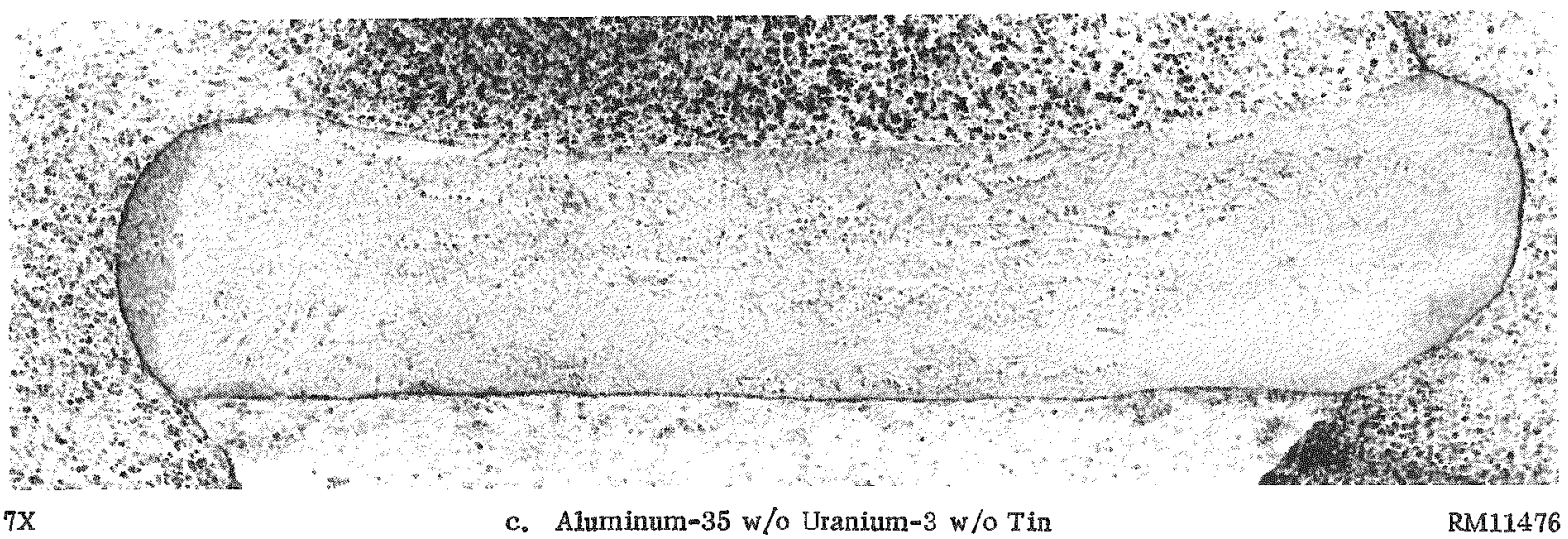

FIGURE 5. ALUMINUM-35 w/O URANIUM SPECIMENS WITH 3 w/O TERNART ADDITIONS HEATED FOR 1 HR AT $540 \mathrm{C}$ AND PRESS FORGED AT 400 TSI TO A 50 PER CENT REDUCTION

Examination of these specimens at 250 and $500 \mathrm{x}$ revealed that in many cases what appeared to be cracks on macroscopic examination were concentrations of compound particles which had been preferentially attacked by the etchant. 
particles exhibited a definite tendency toward spheroidization. This tendency toward less angular compound particles in the alloy may enhance the fabrication characteristics of this alloy. Specimens from the as-cast and fabricated alloys were subsequently examined by $\mathrm{X}$-ray diffraction techniques. The results of the se examinations are given in the following section.

$\mathrm{X}$-Ray Diffraction Studies. As-cast alloys of aluminum-35 w/o uranium with $3 \mathrm{w} / \mathrm{o}$ of the different ternary additions were examined by $\mathrm{X}-\mathrm{ray}$ diffraction. The purpose was to obtain information on the constitution of the alloys that could be related to their fabricability and correlated with the previous metallographic studies.

Specimens in the form of etched needles and filings were used. The etched needles were prepared by wet grinding and etching with a 10 per cent solution of $\mathrm{NaOH}$ in water. The filings were obtained from massive specimens taken from an area in the ingot adjacent to that from which the etched needles were taken. The filings were useful for obtaining a representative diffraction pattern of the alloy. The etched needles were employed in the detection and identification of compounds. In the specimens prepared as etched needles the aluminum pattern was very weak or nonexistent, and the absence of cold work (as would result from filed specimens) made them more suitable for measuring the lattice constant of the $\mathrm{UAl}_{3}$ phase which varied widely from one alloy to another.

The results and observations of the X-ray diffraction studies are shown in Table 2. An examination of the table reveals that among the alloys tested those containing lead, niobium, and palladium exhibited the greatest quantities of UA14. The alloy containing niobium also contained the compound $\mathrm{NbAl}_{3}$. The germanium, silicon, tin, and zirconium alloys exhibited little if any $\mathrm{UAl}_{4}$.

It can also be seen in the table that some etched samples gave no aluminum pattern, while others exhibited this pattern in considerable intensity. This apparent discrepancy is attributed to the differences in microstructure. The samples showing no aluminum metal after etching probably had an interconnected network of compound particles which remained intact after the aluminum was etched away. In samples having isolated compound particles, however, some aluminum would remain on the outside of the sample, and thus register on the diffraction film, regardless of the degree of etching.

The lattice constants measured for the $\mathrm{UAl}_{3}$ are also listed in Table 2. The observed lattice constants varied between 4.225 and $4.282 \mathrm{~A}$. The values reported in the literature range from 4.27 to 4.287 A. If the smaller value from the literature is correct, germanium and tin will increase the lattice constant while the other additions will tend to decrease this measurement. However, for the purpose of discussion the value 4.287 A obtained by Rundle and Wilson (i) is assumed to be correct.

When this value is used all of the measured lattice constants were smaller than the reference value even among the alloys containing lead and zirconium whose atoms are larger than those of either aluminum or uranium. In the case of germanium, silicon, and tin, the lattice-constant reduction could be caused either by solution of 

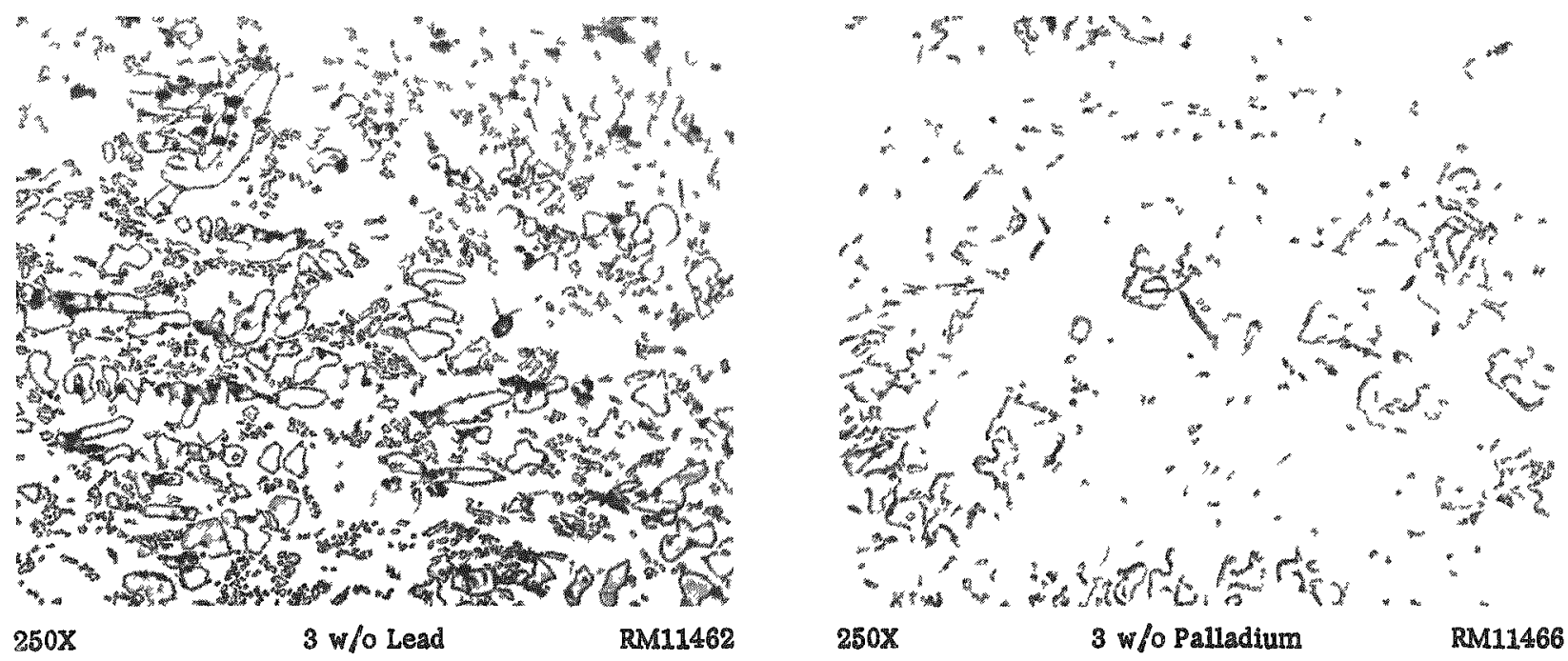

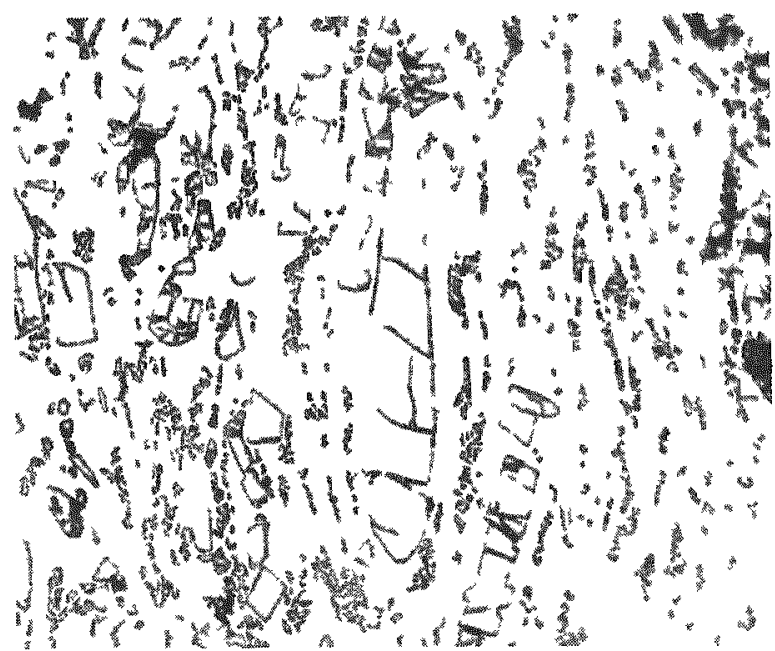

$250 \mathrm{X}$
3 w/o Silicon
RM11472

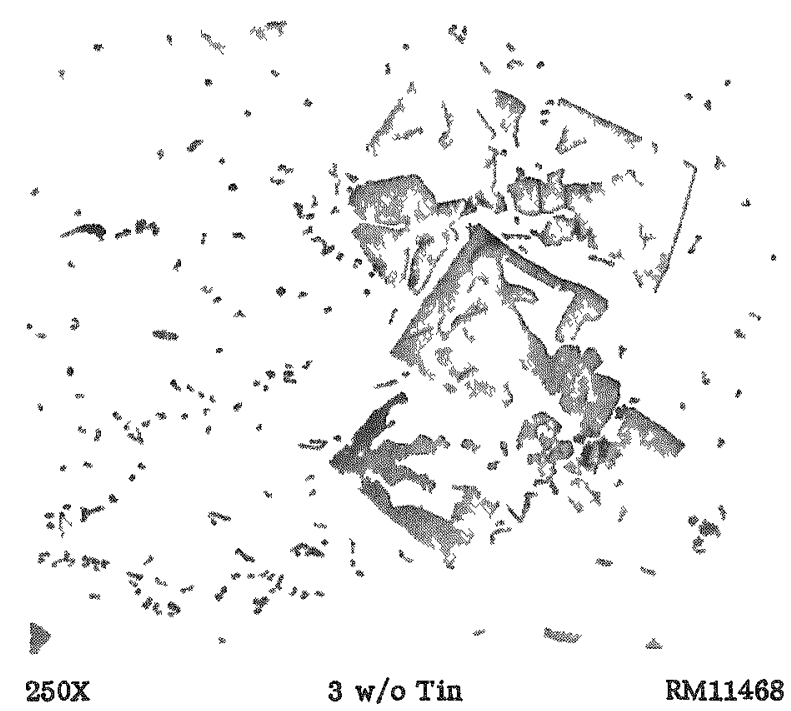

FIGURE 6. PHOTOMICROGRAPHS OF ALUMINUM-35 W/O URANIUM SPECIMENS WITH 3 W/O TERNART ADDITIONS HEATED FOR 1 HR AT 540 C AND PRESS FORGED AT 400 TSI TO A 50 PER CENT REDUCTION

In press forging. the relatively large compounds in the silicon alloy shattered whereas those in the tin alloy remained intact. The cracks which were generated in the niobium alloy can be seen un the $500 \mathrm{x}$ photomicrographs. 

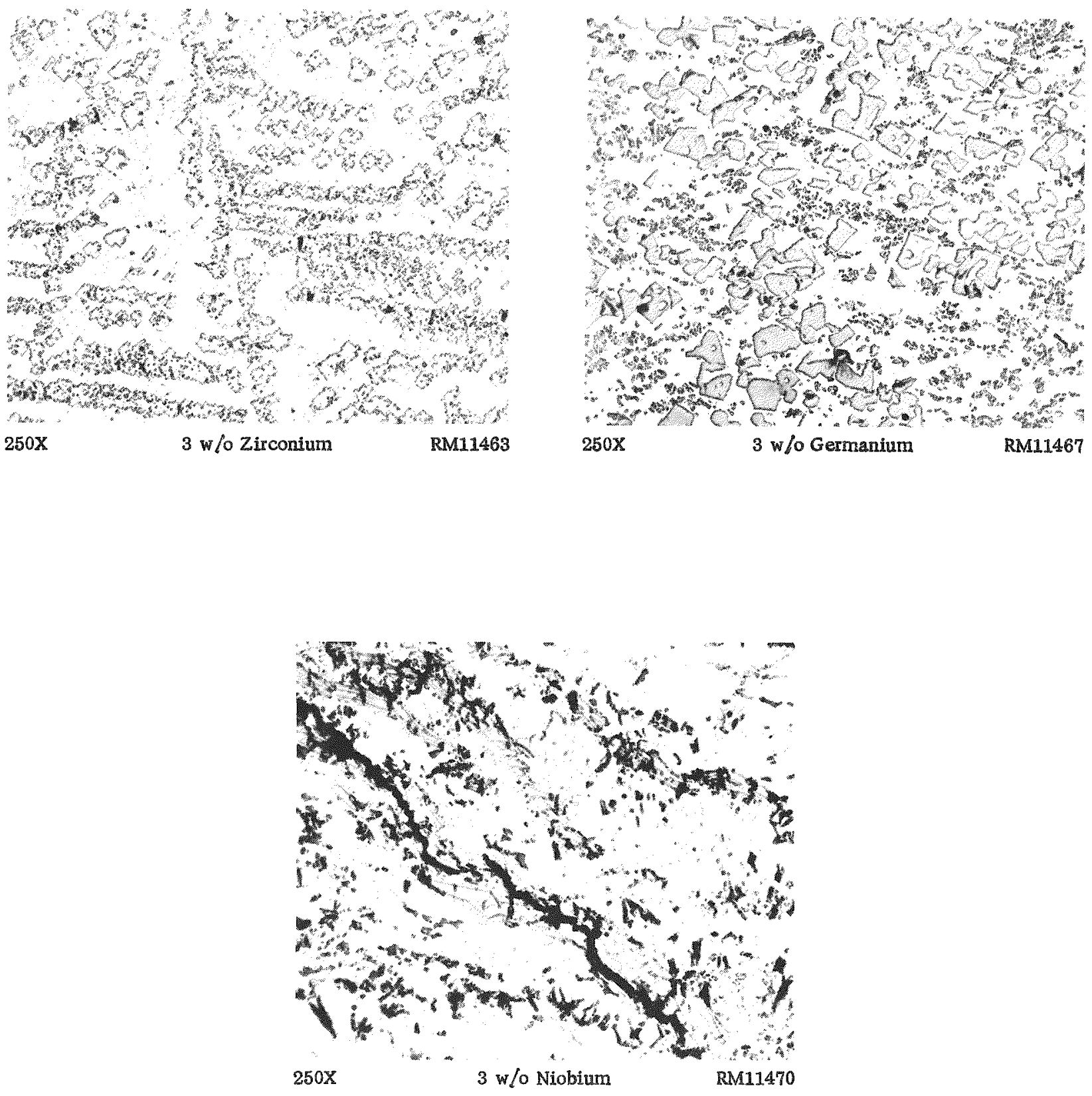

FIG URE 6. CONTINUED 
TABLE 2. X-RAY DIFFRACTION EXAMINATION OF ALUMINUM-35 W/O URANIUM ALLOYS WITH 3 W/O TERNARY ADDITIONS

\begin{tabular}{|c|c|c|c|c|c|c|c|c|c|}
\hline \multirow[b]{2}{*}{$x$-Ray } & \multirow{2}{*}{$\begin{array}{l}\text { Ternary } \\
\text { Additions }\end{array}$} & \multirow{2}{*}{$\begin{array}{c}\text { Atomic Radius(a) } \\
\text { of Element, A }\end{array}$} & \multirow[b]{2}{*}{ Sample Type } & \multicolumn{5}{|c|}{ Intensities of Phase Patterns Observed(b) } & \multirow{2}{*}{$\begin{array}{c}\text { Observed Lattice } \\
\text { Constant of } \\
\mathrm{UAl}_{3}, \mathrm{~A}\end{array}$} \\
\hline & & & & Aluminum & $\mathrm{UAl}_{3}$ & $\mathrm{UAl}_{4}$ & Ternary Additions & Unknowns & \\
\hline 1 & None & -- & Filings & $s$ & VVF & $\mathrm{M}$ & - & 0 & $4.287(a)$ \\
\hline $2 A$ & Germanium & 1.22 & Etched needles & MS & $s$ & 0 & 0 germanium ? & VVF & 4.279 \\
\hline $2 B$ & Germanium & & Filings & $s$ & VS & 0 & 0 & 0 & 4.277 \\
\hline $3 \mathrm{~A}$ & Niobium & 1.43 & Etched needles & 0 & F & S & $\mathrm{MF}-\mathrm{M} \mathrm{NbAl} 3$ & F & $\cdots$ \\
\hline $3 \mathrm{~B}$ & Niobium & -- & Filings & VS & MS & $\mathrm{M}$ & $\mathrm{F} \mathrm{NbAl}_{3}$ ? & $\mathrm{VF}$ & 4.259 \\
\hline $4 \mathrm{~A}$ & Lead & 1.74 & Etched needles & 0 & S & MS & $\begin{array}{l}0 \quad \mathrm{UPb}_{3} \\
\mathrm{VF} \text { lead ? }\end{array}$ & & 4.264 \\
\hline $4 \mathrm{~B}$ & Lead & & Filings & VVS & s & M & $F$ lead? & VF & 4.265 \\
\hline $5 \mathrm{~A}$ & Palladium & 1.37 & Etched needles & $0 ?$ & s & $\mathrm{M}$ & 0 & $\mathrm{VF}$ & 4.265 \\
\hline $5 \mathrm{~B}$ & Palladium & & Filings & VVS & $s$ & MS & 0 & $F$ & 4.269 \\
\hline $6 \mathrm{~A}$ & Silicon & 1.18 & Etched needles & $\mathrm{M}$ & $\mathrm{s}$ & VVF & VF silicon? & $\mathbf{F}$ & 4.225 \\
\hline $6 \mathrm{~B}$ & Silicon & & Filings & $s$ & VS & 0 or $\mathrm{VF}$ & $\begin{array}{l}\text { No uranium-silicon } \\
\text { VF silicon? }\end{array}$ & $\mathrm{VE}$ & 4.225 \\
\hline $7 \mathrm{~A}$ & Tin & 1.40 & Etched needles & F & $\mathrm{M}$ & 0 & VVF tin & VVF+ & 4.282 \\
\hline $7 \mathrm{~B}$ & Tin & & Filings & $S$ & VS & 0 & 0 & VVF+ & 4.284 \\
\hline $8 \mathrm{~A}$ & Zirconium & $1.60,1.62$ & Etched needles & $\mathrm{MF}$ & VS & VVF & 0 & VVF & 4.238 \\
\hline $8 B$ & Zirconium & & Filings & $s$ & VS & 0 & $\mathrm{VVF}, \mathrm{Al}_{3} \mathrm{Zr} ?$ & 0 & 4.237 \\
\hline
\end{tabular}

(a) From BMI-1300.

$\begin{array}{lll}S=\text { strong } & F=\text { faint } & 0=\text { none } \\ M=\text { medium } & V=\text { very } & ?=\text { quantity }\end{array}$

$\mathrm{M}=$ medium $\quad \mathrm{V}=$ very $\quad ?=$ quantity or specie questioned. 
these elements in the compound or by increase in the aluminum-uranium ratio. The lattice-constant $x$ eductions are slight in the cases of germanium and tin. In the case of silicon, the considerable reduction is probably caused by the substitution of silicon in the $\mathrm{UAl}_{3}$ in place of aluminum since silicon is known to dissolve up to $1.65 \mathrm{w} / 0$ in aluminum.

Since the binary contains much $\mathrm{UAl}_{4}$ with little or no $\mathrm{UAl}_{3}$ it is reasonable to assume that those elements which retard the UAl3-UAl4 reaction would prove most beneficial in increasing the fabricating characteristics of the aluminum uranium alloys. These elements were germanium, silicon, tin, and zirconium. From the observations and intexpretations made concerning the lattice constants, germanium, silicon, and tin should prove most effective for this purpose, and of these tin would be most desirable since it would not be as costly as germanium and it is thought to be more compatible with the reprocessing techniques.

$\frac{\text { Preparation and Evaluation of } 3-\text { In. -Diameter }}{\text { Ingots Containing } 3 \mathrm{w} / 0 \text { Ternary Additions }}$

The most important criteria affecting the acceptance of an alloy containing ternary additions are the homogeneity of the cast material, the fabricating characteristics, and the mechanical properties. Therefore, a series of $3-i n$-diameter castings $12 \mathrm{in}$. long containing ternary additions of germanium, lead, niobium, palladium, silicon, tin, and zirconium was prepared. The $3-i n$. diameter was chosen since this quantity of material would require considerable time to solidify and would therefore tend to magnify the segregation tendencies of the alloys. In view of the fact that studies concerned with the physical properties of the alloys were to be made, the alloys were vacuum cast to minimize any microporosity that might occur in air-melted and cast ingots. The techniques employed to vacuum melt and cast these alloys were as follows:

(1) The aluminum was charged into a zirconia crucible.

(2) A pressure of less than $1 \times 10^{-3} \mathrm{~mm}$ of mexcury absolute was maintained over the melt.

(3) The aluminum was melted and its temperature increased to $980 \mathrm{C}$.

(4) Sufficient uranium was introduced into the melt to form an aluminum-35 w/o uranium alloy.

(5) The melt temperature was increased to $1230 \mathrm{C}$ and held for a sufficient time to insure complete solution of the uranium.

(6) The elemental ternary addition was added to the melt and the temperature of the melt was held at $1230 \mathrm{C}$ until all of the addition was dissolved.

(7) The melt was lip poured into a graphite mold with a tapered outside wall. 
Due to the stirring imparted to the melt by the low-frequency induction currents (3000 cycles) and the small-diameter zirconia crucibles, manual stirring was not necessary. From these castings, specimens for radiographic examination, metallography, extrusion, and tensile tests were obtained.

The radiographic examination of the 3 -in.-diameter ingots indicated that both transverse and longitudinal segregation in most cases was more severe in the 3-in.diameter ingots than in the 1-in.-diameter ingots; however, the alloys containing lead, palladium, and tin exhibited very little segregation in either the 1- or 3-in. -diameter castings. For comparison radiographs of sections obtained from the ingots without ternary additions are shown in Figure 7; radiographs of sections from ingots with ternary additions are shown in Figures 8 and 9. Each of the specimens from which the radiographs were obtained was taken from the same area of the respective ingots, and, therefore, should reflect the comparative value of the additives to inhibit segregation or otherwise improve the quality of the cast material. As shown in the prints the leadm, palladium-, and tin-containing alloys were relatively homogeneous from the edge to the center of the ingots. The aluminum $-35 \mathrm{w} / 0$ uranium alloy, which appears homogeneous, exhibited a lacelike pattern of dendritic crystals. These were reflected later in the fracture of the tensile specimens, which exposed large cleavage planes. The silicon alloy exhibited minor cold shuts near the periphery of the specimen and microporosity over much of its area. The zirconium alloy shown in the photograph reveals microporosity toward the center of the specimen. This porosity extended approximately $1 / 4$ in. in the specimen and was not detected elsewhere in the ingot.

One of the simplest and yet most informative tests that can be used to evaluate the effects of ternary additions on the mechanical properties of the aluminumm uranium alloys is the tensile test. Of the information available from these tests perhaps the data for the tensile strength, the per cent elongation, and the per cent reduction in area are the most significant. The tensile or ultimate strength should afford some indication of the partitioning of the additives between the matrix and the compound. Elongation and reduction-in-area figures are indicative of the ductility of the material. Of these, the reduction in area gives an indication of the total amount of deformation that may be accomplished and is useful in comparing the relative capacities for deformation in the alloys. The elongation can be more nearly applied to the fabrication of the alloys.

For the purpose of this study it was decided to test duplicate specimens of each composition at each of two crosshead speeds. The crosshead speeds used were $0.02 \mathrm{in}$. per min and $0.10 \mathrm{in.} \mathrm{per} \mathrm{min.} \mathrm{The} \mathrm{data} \mathrm{from} \mathrm{these} \mathrm{tests} \mathrm{are} \mathrm{shown} \mathrm{in} \mathrm{Table} 3$. These speeds differ by a factor of five, which should have been sufficient to indicate the strain-rate sensitivity of the alloys. There was no appreciable difference exhibited by the alloys when tested at the different crosshead speeds. It can also be seen that the aluminum- $35 \mathrm{w} / \mathrm{o}$ uranium alloy exhibited a considerable increase in tensile strength when compared with the aluminum- $25 \mathrm{w} / 0$ uranium alloy. Of the alloys containing ternary additions only the silicon-alloy specimens exhibited tensile strengths less than that exhibited by the binary alloy. Subsequent tests indicated that the reasons for the low tensile strength exhibited by these alloys could have been caused by the microporosity noted within the specimens. Figure 10 shows typical fractures of the tensile specimens. The fractures exhibited by the alloys containing the additives are

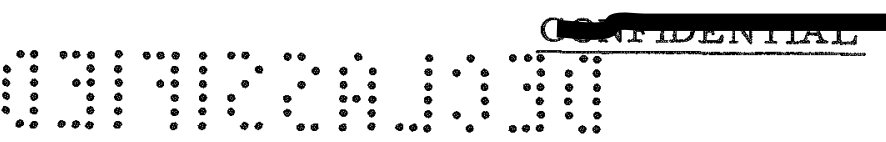



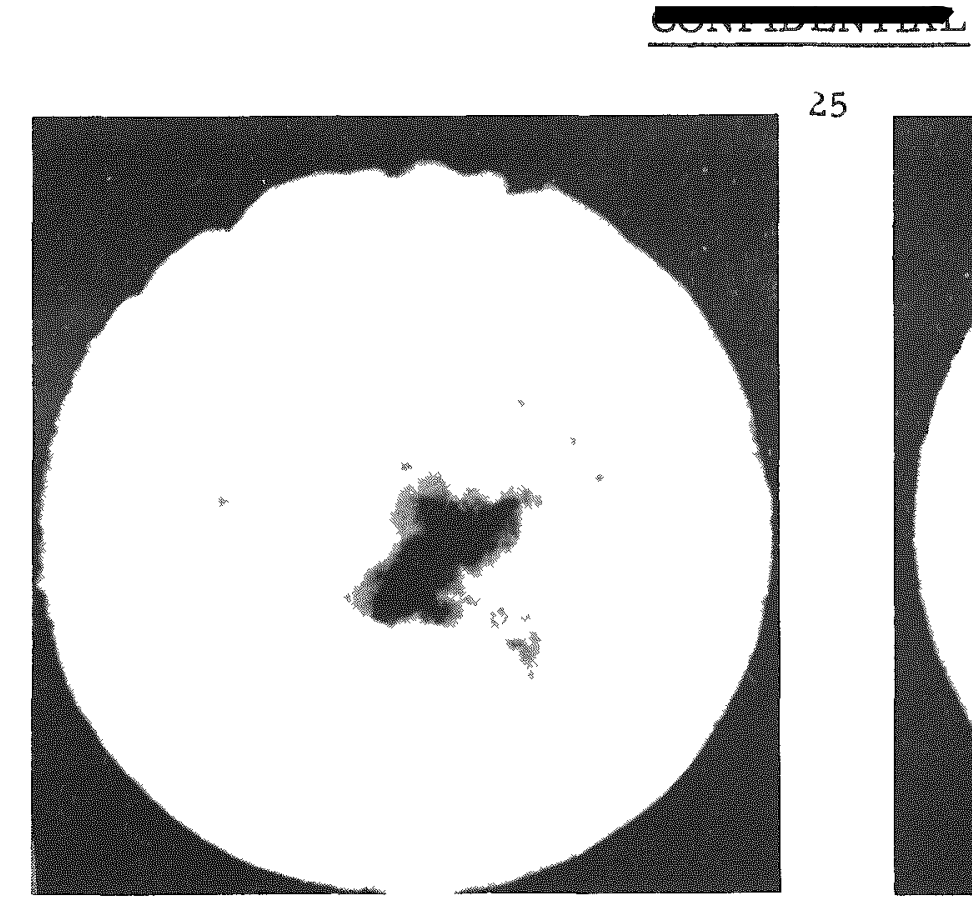

25

$1 \mathrm{X}$

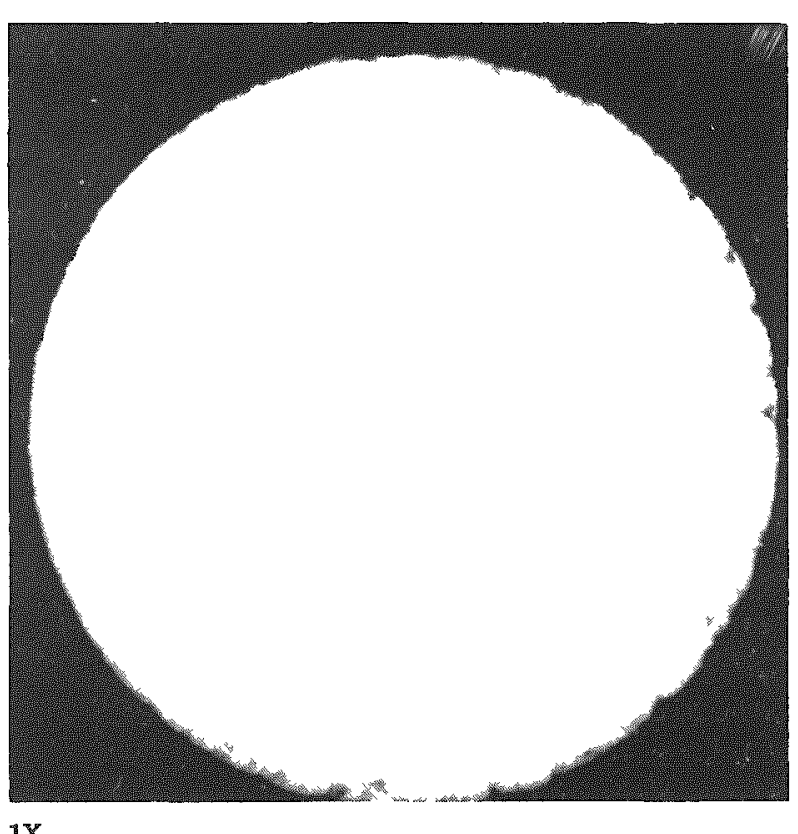

FIGURE 7. RADIOGRAPHS OF 3-IN.-DIAMETER ALUMINUM-35 W/0 URANIUM INGOTS WITHOUT TERNARY ADDITIONS

The apparently homogeneous material in the photo at right exhibited a lacelike pattern of dendritic crystals.

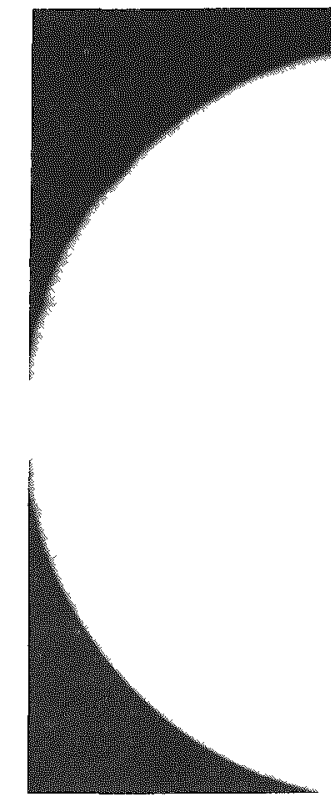

1X

Aluminum-35 w/o Uranium -3 w/o Palladium

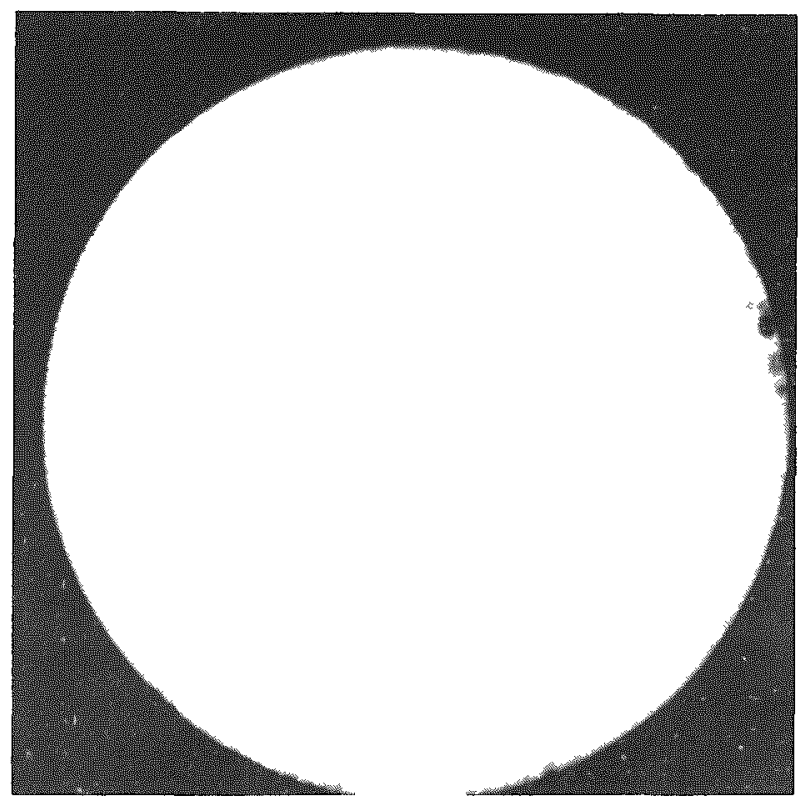

IX

FIGURE 8. RADIOGRAPHS OF 3-IN, -DIAMETER ALUMINUM॰35 W/0 URANTUM INGOTS WITH PALIADIUM OR TIN ADDITIONS

These prints illustrate the edgemtom center homogeneity obtained in the casting containing these additions. 


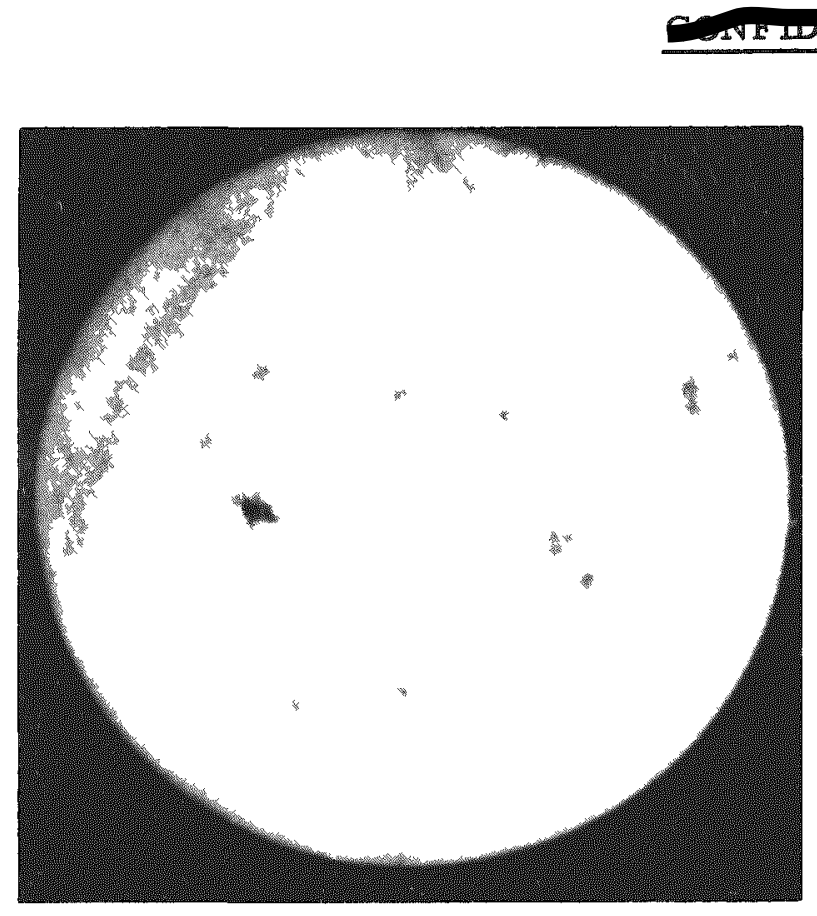

1X
26

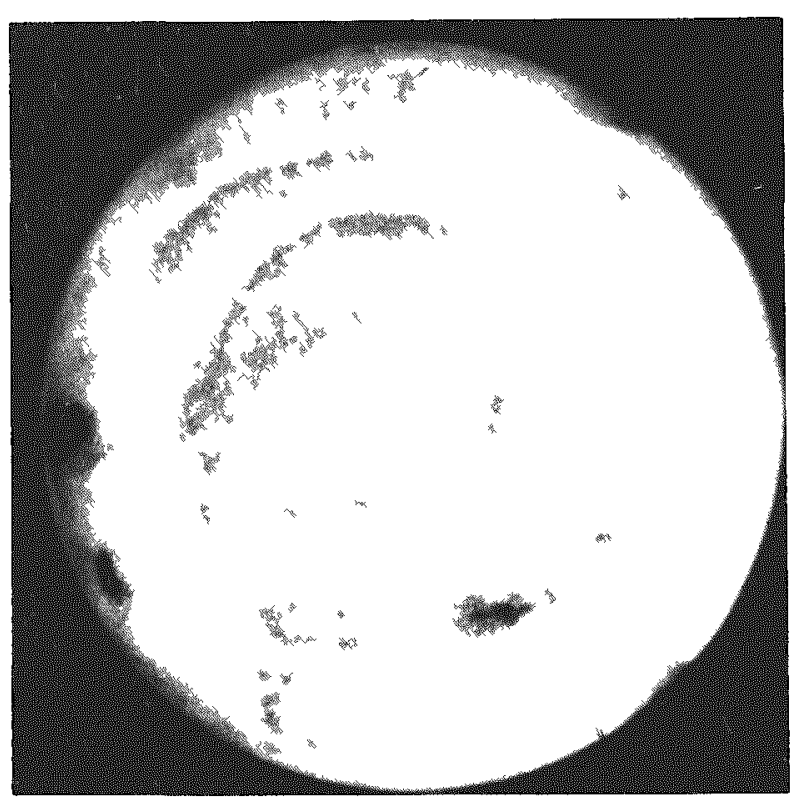

IX

Aluminum-35 w/o Urandum-3 w/o Lead

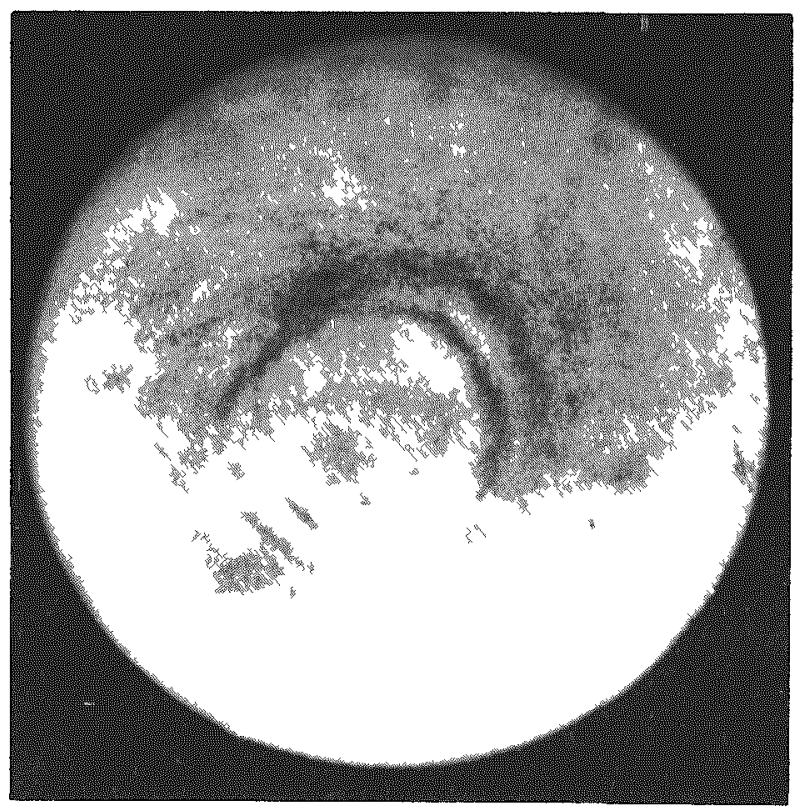

IX

Aluminum-35 w/o Uranium-3 w/o Zirconîn

FIGURE 9. RADIOGRAPHS OF 3-IN.-DIAMETER ALUMINUM-35 W/0 URANIUM INGOTS WITH LEAD. SILICON, OR ZIRCONIUM ADDITIONS

The dark areas shown near the edge of the sillicon alloy are the result of cold shuts: those near the center of the silicon and zirconium ingots are the result of microporosity which extended less than $1 / 4$ in. through the specimens. 


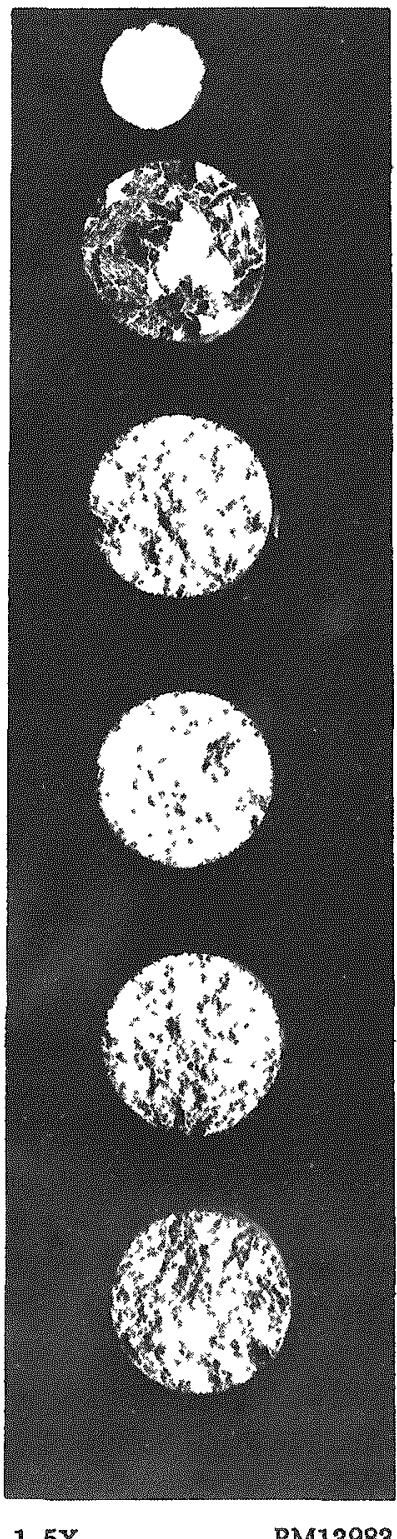

Aluminum-25 $w / 0$ uranium

Aluminum-35 w/o uranium

Aluminum-35 w/o uranium-3 $w / 0$ tin

Aluminum-35 w/o uraniume3 $w / 0$ silicon

Aluminum-35 w/o uranium-3 w/o zirconium

FIGURE 10. MACROGRAPH OF REPRESENTATIVE FRACTURED SURF ACES OF TENSILE SPECIMENS

This view illustrates the refinement in structure of the alloys attributed to the ternary additions. 
TABLE 3. TENSILE DATA OBTAINED FROM AS-CAST MATERIAL

All Values Represent an Average for the Number of Specimens Indicated

\begin{tabular}{|c|c|c|c|c|c|c|c|}
\hline $\begin{array}{c}\text { Alloy Composition } \\
\text { (Balance Aluminum), } \\
\text { w/o }\end{array}$ & $\begin{array}{l}\text { Number of } \\
\text { Specimens }\end{array}$ & $\begin{array}{l}\text { Original } \\
\text { Dimensions, } \\
\text { in. }\end{array}$ & $\begin{array}{l}\text { Fracture } \\
\text { Dimensions, } \\
\text { in. }\end{array}$ & $\begin{array}{c}\text { Elongation, } \\
\text { per cent }\end{array}$ & $\begin{array}{l}\text { Reduction } \\
\text { Area, } \\
\text { per cent }\end{array}$ & $\begin{array}{l}\text { Tensile } \\
\text { Load, } \\
\text { Ib }\end{array}$ & $\begin{array}{l}\text { Tensile } \\
\text { Strength, } \\
\text { psi }\end{array}$ \\
\hline 25 uranium & 8 & 0.508 & 0.504 & 1.2 & 1.6 & 1570 & 7,200 \\
\hline 35 uranium & 8 & 0.507 & 0.500 & 1.3 & 2. 1 & 3430 & 17,000 \\
\hline 35 uranium -3 tin & 4 & 0.505 & 0.491 & 7.6 & 5.5 & 3870 & 19,100 \\
\hline 35 uranium-3 palladium & 4 & 0.509 & 0.506 & 1.3 & 1.2 & 4260 & 21,000 \\
\hline 35 uranium-3 silicon & 4 & 0.504 & 0.496 & 2.2 & 3.0 & 2500 & 12,400 \\
\hline 35 uranium-3 lead & 4 & 0.508 & 0.503 & 2.3 & 2.2 & 3960 & 19,700 \\
\hline 35 uranium-3 zirconium & 4 & 0.508 & 0.500 & 2.6 & 3.4 & 3980 & 19,800 \\
\hline
\end{tabular}


typical of fine-grain material and show none of the distinctive cleavage planes exhibited by the binary tensile specimens.

An examination of the elongation of the various specimens reveals that those specimens containing lead, silicon, tin, and zirconium exhibited ductilities superior to those shown by the binary alloys. The increased ductility of these alloys is attributed to the increased aluminum in the matrix through the retention of all or part of the $\mathrm{UAI}_{3}$. The elongation of the specimens containing tin was extremely good when compared with the binary alloys, and, since elongation is a measure of the material's ability to undergo deformation in forming operations, it would indicate that this alloy is superior in this respect to the other alloys tested. On this basis the zirconium-containing alloy should also be more amenable to fabrication than the binaries and at least equivalent to the silicon-containing alloy.

\section{Extrusion Studies}

Since the objective of this study was the investigation of the feasibility of enhancing the fabricating and casting characteristics of the alloy by the addition of a third element, and since the contemplated fabrication technique to be used was extrusion, those alloys which appeared to offer the greatest possibility of being amenable to this fabrication technique were extruded. As a base for comparison purposes binary alloys of aluminum- $25 \mathrm{w} / 0$ uranium and aluminum $-35 \mathrm{w} / \mathrm{o}$ uranium were also extruded utilizing similar conditions.

The 2.75-in.-diameter extrusion specimens were prepared from the 3-in.diameter ingots by machining. The ingots were then inserted into $3-$ in $_{a}-O D$ aluminum cans and sealed with 1/4-in, -thick welded end caps. These specimens were coated with a colloidal suspension of graphite in water and heated to $430 \mathrm{C}$. The material was extruded through a flat-face die at $315 \mathrm{C}$; the follow block was also at $315 \mathrm{C}$. A ram speed of 20 in. per min was employed for all compositions.

During extrusion a record of the pressures required to extrude the material was obtained through the use of a Bacharach gage connected to the hydraulic system of the press. The pressures indicated by this method as necessary for the extrusion of the materials under these conditions are shown in Table 4.

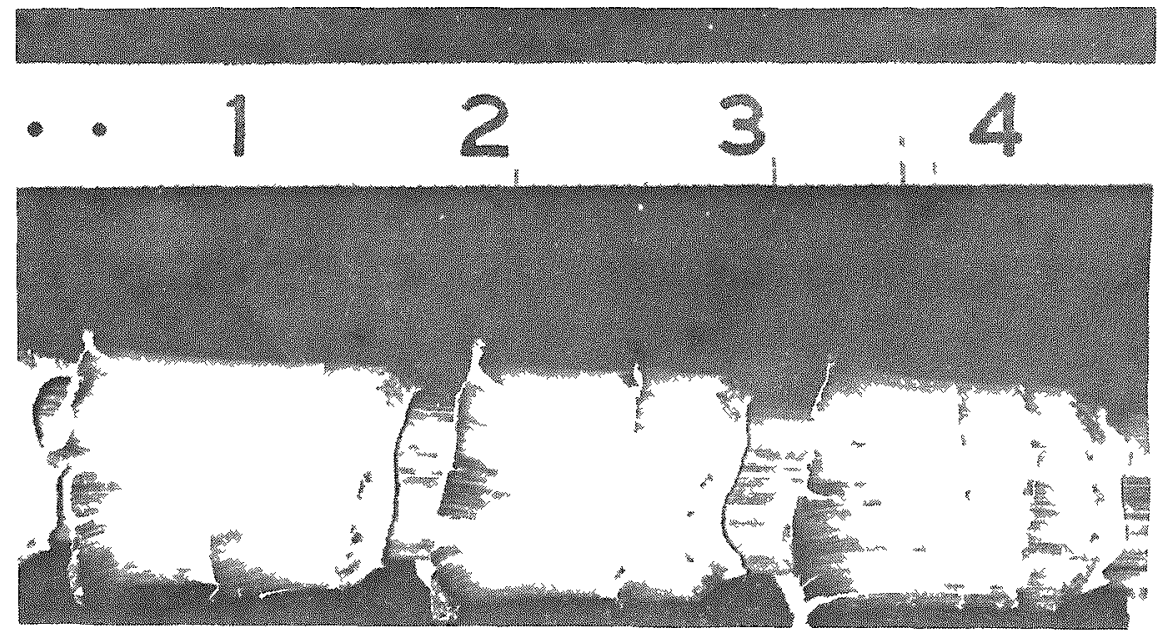

FIGURE 11. EXTRUDED ROD SHOWING "RATTLESNAKING"

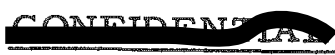


TABLE 4. TENSILE TEST OF ALUMINUM-URANIUM ALLOYS

\begin{tabular}{|c|c|c|c|c|c|}
\hline \multirow{2}{*}{$\begin{array}{c}\text { Alloy Composition } \\
\text { (Balance Aluminum), } \\
\text { w/o }\end{array}$} & \multicolumn{2}{|c|}{$\begin{array}{c}\text { Ultimate } \\
\text { Tensile Strength, } \\
\text { psi }\end{array}$} & \multicolumn{2}{|c|}{$\begin{array}{l}\text { Reduction } \\
\text { in Area, } \\
\text { per cent }\end{array}$} & \multirow{2}{*}{$\begin{array}{c}\text { Maximum } \\
\text { Extrusion } \\
\text { Pressure, } \\
\text { tsi }\end{array}$} \\
\hline & As Cast & Extruded & As Cast & Extruded & \\
\hline 35 uranium & 17,000 & 21,500 & 2.35 & 1.85 & 12.2 \\
\hline 35 uranium -3 tin & 19,000 & 17,900 & 4. 34 & 3.5 & 9.37 \\
\hline 35 uranium -3 zirconium & 19,600 & 17,000 & 3.75 & 3.62 & 9.37 \\
\hline 35 uranium-3 silicon & 12,500 & 22,000 & 3.5 & 3.75 & 9.37 \\
\hline
\end{tabular}

The evaluation of the extruded material consisted of visual inspection and metallographic examination supplemented by tensile tests on the ternary alloys containing silicon, tin, and zirconium and the binary aluminum-35 w/o uranium. The visual examination of the extruded rod showed that "rattlesnaking" had occurred to a limited extent in one of the two binary alloys containing $35 \mathrm{w} / \mathrm{o}$ uranium and to a much greater extent in the alloy containing lead. The appearance of the rattlesnaking encountered in the lead-containing alloy is shown in Figure 11. The specimen was taken from that portion of the extruded material where aluminum envelopes the alloy core. The reasons for this type of defect in extruded materials have not been determined, though in the case of the lead-containing alloy it could have been aggravated by the presence of the free lead detected by metallographic and $\mathrm{X}$-ray diffraction studies. Of the alloys examined, the best surfaces (both cladding and interfaces) were exhibited by the alloys containing silicon, tin, and zirconium.

The metallographic examination of the extruded material revealed that the alloys containing tin and zirconium contained little or no microporosity due to fractures in the compound or in areas adjacent to the compound. The simple binary alloys exhibited microporosity in the matrix and in the compounds due to fracturing. This is shown in the photomicrographs in Figure 12. The other extruded materials exhibited microstructures very similar to those noted in the press-forged specimens of the same composition.

In an effort to ascertain the effects of extrusion on the physical properties of the alloys, tensile specimens were obtained from the as-extruded rods containing silicon, tin, and zirconium and the binary aluminum-35 w/o uranium. These specimens were ruptured using a crosshead speed of $0.02 \mathrm{in}$. per min. The results of these tests are summarized in Table 4. An examination of the table reveals that in the as-cast condition the alloys containing tin and zirconium exhibited greater ultimate strength than either the binary alloy or the alloy containing silicon; whereas, in the extruded condition the opposite was true. The latter two exhibit increases in tensile strength after 

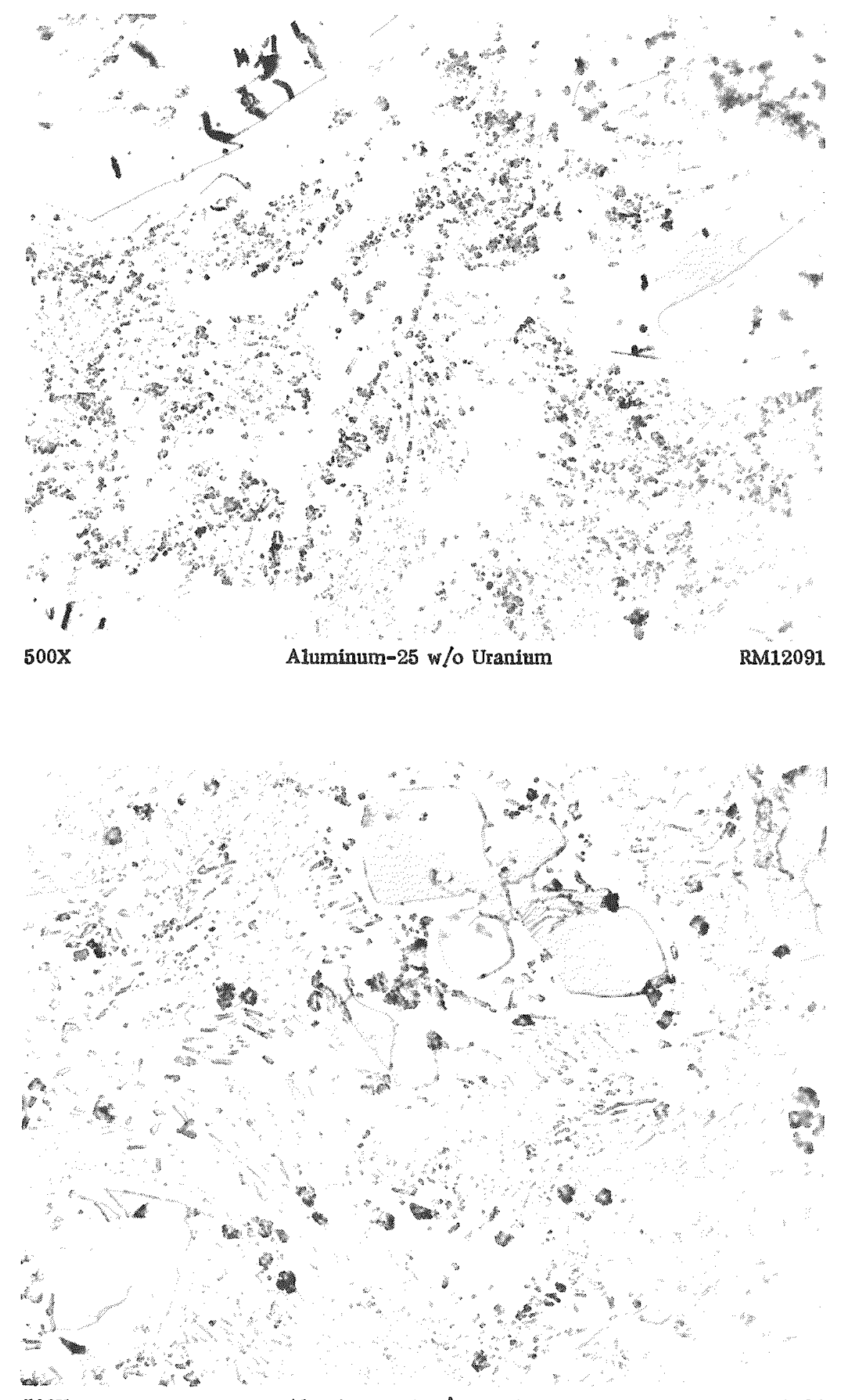

FIGURE 12. EXTRUDED MATERIAL FROM BINARY ALLOYS EXHIBIT ING MICROPOROSITY IN THE MATRIX AND IN THE COMPOUNDS DUE TO FRACTURING

Little or no fracturing of compounds was detected in the specimens containing tin or zirconium. 
fabricating. An explanation of the large increase in strength shown by the alloy containing silicon must lie in casting quality since the as-cast strength was abnormally low when compared with the other alloys. The reductions in area of the alloys containing the ternary additions were greater than the reductions in area of the binary alloy in both the as-cast and fabricated condition and are attributed to the reduction in the amount of compound in the ternary alloys. In the last column in the table are the values obtained from one series of alloys in effecting a 16:1 reduction of a 3-in.-diameter extrusion blank. As stated previously these values were obtained from a Bacharach gage connected to the hydraulic system of the extrusion press. From these values it appears that the reduction in compound results in a reduction in the extrusion pressure required.

\section{CONCLUSION}

One possible method of effecting improvements in the casting and fabricating characteristics of aluminum-uranium alloys is with suitable ternary additions that refine the cast structure and/or suppress the $\mathrm{UAl}_{3}-\mathrm{UAl}_{4}$ peritectic reaction. In so doing, the mechanical properties are improved because the size and shape of the compound present are changed and/or a greater quantity of free aluminum is present in the as-cast structure. Initially in this study, the effects of selected alloy additions at or near the 3 a/o level were evaluated. The additions were: copper, gadolinium, germanium, lead, lithium, magnesium, nickel, niobium, palladium, silicon, sodium, tin, titanium, and zirconium. The evaluation of these melts revealed that gadolinium and lithium caused extensive porosity in the castings; palladium and tin refined the compound particle size; copper, nickel, and titanium increased the amount of compound present in the alloys. At the 3 a/o concentration only the palladium-containing material did not exhibit extensive microcracking in specimens press forged at $540 \mathrm{C}$. The metallographic examination of the lead alloy revealed the presence of free lead. In one instance the sodium alloy exhibited a refined microstructure but the results could not be duplicated.

Later studies were concerned with the qualities of alloys containing $3 \mathrm{w} / 0$ additions of germanium, lead, nickel, niobium, palladium, silicon, tin, titanium, and zirconium. The effects of these elemental additions were evaluated by radiographic examination of as-cast material, metallographic examination of as-cast and fabricated specimens, tensile tests on as-cast and extruded material, and X-ray diffraction. Radiographic examinations revealed that the tin- and lead-alloy ingots were more homogeneous than either the binary aluminum-35 w/o uranium ingots or the ingots containing other ternary additions. Tensile tests showed that asmcast alloys of silicon, tin, and zirconium were superior to the as-cast aluminum $-35 \mathrm{w} / \mathrm{o}$ uranium alloy in both the elongation and the reduction in area obtained. Also the extrusion pressure necessary to effect a 16:1 reduction in the alloys was decreased approximately 25 per cent with the addition of the aforementioned silicon, tin, and zirconium. Metallographic and X-ray diffraction studies showed that germanium, silicon, tin, and zirconium were effective in retaining $\mathrm{UAl}_{3}$, thereby increasing the amount of matrix present in the alloys. 


\section{3 and 34}

On the basis of these studies the factors which favor tin and/or zirconium as a ternary addition for improving the casting and fabricating characteristics of the aluminum-35 w/o uranium alloy are summarized below:

(1) Of the alloys upon which tensile tests were conducted, the greatest ductility was exhibited by the tin alloy. Zirconium was also superior in ductility to the binary alloy.

(2) The alloy containing tin exhibited the least segregation when cast into 3-in. - diameter graphite molds.

(3) No fragmentation or rupturing was observed in the alloys of tin or zirconium.

(4) Extrusion studies indicated that less pressure was required for a given reduction when tin or zirconium was added to the binary aluminum- 35 w/o uranium alloy.

The advantages inherent in the improvements noted could be realized in the production fabrication of fuel elements. Not only was this demonstrated by the limited extrusion studies but also by improved mechanical properties of the alloys as determ mined by tensile, tests. An indication of the stability of the $\mathrm{UAl}_{3}$ retained can be deduced from the fact that no $\mathrm{UAl}_{4}$ was detected in $3 \mathrm{w} / 0$ tin- or zirconiummalloy material that had been heated to $430 \mathrm{C}$ and extruded.

Future studies are planned in which the alloy composition will be optimized with consideration given to corrosion and mechanical properties and the effectiveness of $\mathrm{UAl}_{3}$ retention.

\section{REFERENCES}

(1) Uranium Alloy Newsletter, Edward Epremian, editor, WASH-703 (August 1957).

(2) Thurber, W. C., and Beaver, R. S., "Development of Silicon Modified 48 w/o Uranium-Aluminum Alloys for Aluminum Plate Type Fuel Elements", ORNL2602 (March 23, 1959).

NED/ELF/RFD:jvo 